\title{
Novel Insights into Pyrrolizidine Alkaloid Toxicity and Implications for Risk Assessment: Occurrence, Genotoxicity, Toxicokinetics, Risk Assessment-A Workshop Report
}

Authors

Dieter Schrenk ${ }^{1}$, Jörg Fahrer ${ }^{1}{ }^{\mathbb{D}}$, Ashley Allemang ${ }^{2}$, Peter Fu ${ }^{3}$, Ge Lin ${ }^{4}$, Catherine Mahony ${ }^{5}$, Patrick P.J. Mulder ${ }^{6}$, Ad Peijnenburg $^{6}$, Stefan Pfuhler ${ }^{2}$, Ivonne M.C.M. Rietjens ${ }^{7}$, Benjamin Sachse ${ }^{8}$, Barbara Steinhoff ${ }^{\circledR}{ }^{\mathbb{D}}$, Anja These $^{8}$, John Troutman ${ }^{2}$, Jacqueline Wiesner ${ }^{10}$

Affiliations

1 Food Chemistry and Toxicology, Technical University of Kaiserslautern, Kaiserslautern, Germany

2 Procter \& Gamble, Mason, $\mathrm{OH}$, USA

3 National Center for Toxicological Research, Food and Drug Administration, Jefferson, AR, USA

4 School of Biomedical Sciences, Faculty of Medicine, The Chinese University of Hong Kong, Hong Kong SAR

5 Procter \& Gamble, Technical Centres Limited, Weybridge, Surrey, United Kingdom

6 Wageningen Food Safety Research, Wageningen University \& Research, Wageningen, the Netherlands

7 Division of Toxicology, Wageningen University, Wageningen, the Netherlands

8 German Federal Institute of Risk Assessment (BfR), Berlin, Germany

9 German Medicines Manufacturers' Association (BAH), Bonn, Germany

10 Federal Institute for Drugs and Medical Devices (BfArM), Bonn, Germany

Key words

genotoxicity, hepatotoxicity, pyrrolizidine alkaloids, risk assessment, structure-activity relationship, toxicokinetics

received

May 13, 2021

accepted after revision

September 15, 2021

published online

October 29, 2021

Bibliography

Planta Med 2022; 88: 98-117

DOI $10.1055 / \mathrm{a}-1646-3618$

ISSN 0032-0943

(C) 2021. Thieme. All rights reserved.

Georg Thieme Verlag KG, Rüdigerstraße 14,

70469 Stuttgart, Germany
Correspondence

Dieter Schrenk

Food Chemistry and Toxicology, Technical University

of Kaiserslautern

Erwin-Schroedinger-Straße 52, 67663 Kaiserslautern, Germany

Phone: + 496312053217 , Fax: + 496312054398

schrenk@rhrk.uni-kl.de

Correspondence

Jörg Fahrer

Food Chemistry and Toxicology, Technical University of Kaiserslautern

Erwin-Schroedinger-Straße 52, 67663 Kaiserslautern, Germany

Phone: + 496312052974 , Fax: + 496312054398

fahrer@chemie.uni-kl.de

Supplementary material is available under

https://doi.org/10.1055/a-1646-3618

\section{ABSTRACT}

This paper reports on the major contributions and results of the 2nd International Workshop of Pyrrolizidine Alkaloids held in September 2020 in Kaiserslautern, Germany. Pyrrolizidine alkaloids are among the most relevant plant toxins contaminating food, feed, and medicinal products of plant origin. Hundreds of PA congeners with widespread occurrence are known, and thousands of plants are assumed to contain PAs. Due to certain PAs' pronounced liver toxicity and carcinogenicity, their occurrence in food, feed, and phytomedicines has raised serious human health concerns. This is particularly true for herbal teas, certain food supplements, honey, and certain phytomedicinal drugs. Due to the limited availability of animal data, broader use of in vitro data appears warranted to improve the risk assessment of a large number of relevant, 1,2-unsaturated PAs. This is true, for example, for the derivation of both toxicokinetic and toxicodynamic data. These efforts aim to understand better the modes of action, uptake, metabolism, elimination, toxicity, and genotoxicity of PAs to 
enable a detailed dose-response analysis and ultimately quantify differing toxic potencies between relevant PAs. Accordingly, risk-limiting measures comprising production, market- ing, and regulation of food, feed, and medicinal products are discussed.

\section{Introduction}

In September 2020, the 2nd International Workshop on Pyrrolizidine Alkaloids (PAs) was held online entitled "Novel insights into pyrrolizidine alkaloid toxicity and implications for risk assessment: Occurrence, genotoxicity, toxicokinetics, risk assessment". This report aims to give an overview of the broad spectrum of contributions of the workshop covering diverse aspects of basic science, its application, and related regulatory action concerning PAs in food, including food supplements, feed, and herbal medicinal products. The conclusions represent the common views of the contributors. If original data are presented, they are in the process of publication or will be published in this special issue or elsewhere.

The findings of relatively high levels of PAs in certain food items and herbal medicinal products [1-3] have triggered considerable interest in more detailed data on occurrence, levels, exposure, toxicity, and mode of action of PAs. Previous efforts to assess the risk for humans [4-6] indicated that the current exposure might be of concern, at least for certain consumers. Efforts to mitigate PA levels in such products focused on avoiding contaminations of plant preparations with PA plants [7-9].

Acute intoxications with PAs may occur under conditions of erroneous use of PA plants resembling plants traditionally used for herbal infusions $[10,11]$. Intoxications are frequently seen in domestic animals [12]. Both in humans and animals, the chronic toxicity of PAs is of particular interest since hepatotoxic and genotoxic events may accumulate over time and result in irreversible damage such as chronic liver failure or cancer (see below).

Asteraceae, Boraginaceae, and Fabaceae are the major plant families comprising large numbers of PA-synthesizing species. Overall, more than 600 different PAs (congeners) have been found in nature with their major structural constituents, a necine base (pyrrolizidine ring), and 1 or more necic acid(s) bound to the necine base via ester bridges ( $\bullet$ Fig. 1 ). The PAs can be subdivided into monoesters, open diesters, and cyclic diesters. All toxicologically relevant PAs bear a double bond in the 1,2-position of the necine base and require further metabolic oxidation of the pyrrolizidine ring to be activated to the reactive, toxic pyrrolic metabolites.

A hallmark of acute and sub-acute PA toxicity is the damage seen to liver sinusoidal endothelial cells and hepatocytes seen, for example, in laboratory and domestic animals [13]. In humans and animals, necrosis of sinusoidal endothelial cells leads to venoocclusive disease and liver failure, while pulmonary venous endothelial cells may also be affected [14]. Upon chronic treatment of rodents with PAs, liver cell carcinoma, and haemangio-endothelial sarcoma, and in some instances, extra-hepatic tumors of the lung, pancreas, and intestine may occur [5].

The reactive dehydro-pyrrolizidine (DHP) esters and/or free DHP (pyrrolic metabolites)-form covalent adducts with proteins and nucleic acids (reviewed in [1]). Several PAs were shown to be genotoxic in bacteria, insects, and mammalian cells in culture. Similarly, pyrrolic metabolites are most probably also responsible for non-neoplastic damage of target cells and tissues. Their formation depends on oxidative enzymes, most notably cytochromes P450. Although these pyrrolic metabolites are most active in parenchymal hepatocytes, it is assumed that (secondary) metabolites still being reactive may be released from the hepatocytes and could thus affect other cell types. Oxygenation at the heterocyclic nitrogen occurring in plants and liver microsomes leads to PA $\mathrm{N}$-oxides. These are not metabolized directly into pyrrolic metabolites but can be reduced to the parent PA and activated as described above [15]. Thus, the toxic potency of PA-derived $\mathrm{N}$-oxides may be lower than that of the parent PA. However, the difference is likely to depend on the actual conditions, such as the redox state of the chemical milieu or to reductase activities in intestinal bacteria and tissues of the host.

The current risk assessment of PAs is limited by the relatively small number of congeners tested in animal studies upon chronic exposure. One study in rats analyzing the tumorigenicity of lasiocarpine has been used initially to derive a point of departure for chronic risk assessment of PAs [5]. Because of several methodological drawbacks, EFSA later selected a long-term study with riddelliine $[1,16]$ as the more adequate basis.

Based on a limited amount of data, Merz and Schrenk [17] published interim relative potency (iREP) factors to describe the toxic and genotoxic potency of 1,2-unsaturated PAs. Briefly, this approach is based on fundamental structural considerations together with acute toxicity data from rodents, cytotoxicity data in mammalian cell culture, and genotoxicity data in Drosophila. However, the use of in vitro data on toxicity and genotoxicity of PAs has been hampered by a lack of data on their toxicokinetics in intact organisms. In addition, more work is needed on the exact mode of action (MoA) of highly toxic and carcinogenic 1,2-unsaturated congeners. Furthermore, PA-derived $\mathrm{N}$-oxides may need special considerations [18] since the intestinal microflora can substantially convert $\mathrm{N}$-oxides into the more toxic parent PAs after oral exposure, while $\mathrm{N}$-oxides can also be reduced by tissues and cells of the host [19].

\section{PA Levels in Food: Current Situation and Perspectives}

Except for a very small number of species (most notably: borage [Borago officinalis]), plants known to produce PAs are not intentionally consumed. Until the early 2000s, little was known about the actual presence of PAs in food products, except for their occurrence in honey and pollen products. Since honeybees also forage on PA-containing plants, it was recognized early that residues could be transferred to honey and pollen products [20]. However, 

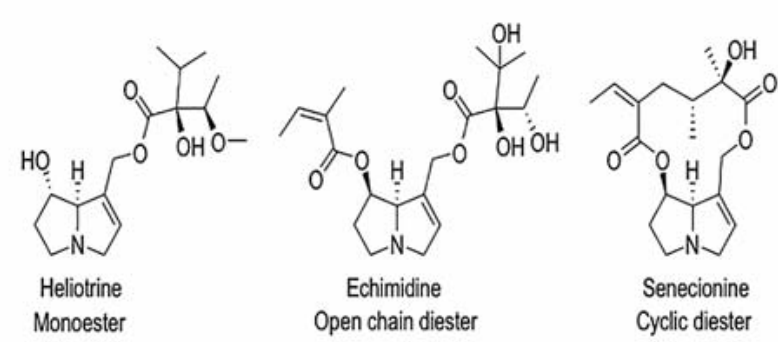

- Fig. 1 Major types of 1,2-unsaturated pyrrolizidine alkaloids, members of the heliotrine type (heliotrine), and the retronecinetype (echimidine and senecionine)

over the past decade, it has become evident that many food categories can contain PAs. These PAs are, in most cases, introduced in the food chain due to contamination with PA-containing weeds, often during primary production.

The availability of highly selective and sensitive techniques, such as liquid chromatography coupled to tandem mass spectrometry (LC-MS/MS) and LC coupled to high-resolution MS (LCHRMS), has had a great impact on the possibilities to monitor food products for low levels of toxic substances, including PAs. Limits of quantification for PAs typically are in the low or sub $\mu \mathrm{g} /$ $\mathrm{kg}$ level. The application of LC-MS/MS in a routine laboratory environment revealed the ubiquitous presence of PA residues in imported honey [21,22]. At first, a comprehensive analysis of food samples was somewhat hampered due to the low number of PAs commercially available as analytical standards, but this has improved significantly. Currently, routine methods typically contain 30 or more analytes. Following the reports on honey, the widespread presence of PAs has been reported in many different types of herbal teas (as well as in tea made from Camellia sinensis), in herbal food supplements, and somewhat more recently, in culinary herbs and spices and leafy salads ( $\triangleright$ Table $\mathbf{1})$.

Besides the PA-producing plant borage, PA levels exceeding $10 \mathrm{mg} / \mathrm{kg}$ have been found in culinary herbs, particularly oregano. The contamination is often due to co-harvested Heliotropium spp. In herbal teas and supplements, the typical contamination level is somewhat lower, with concentrations occasionally exceeding $1 \mathrm{mg} / \mathrm{kg}$. The causative plants are more diverse, but Senecio and Boraginaceae spp are the most common. In retail honey, PA levels are typically well below $100 \mu \mathrm{g} / \mathrm{kg}$ and predominantly originate from Boraginaceae spp. Products derived from animal origin (dairy products, eggs, meat) appear of lesser concern, primarily because the transfer rate of PAs is relatively low due to extensive metabolism in the animals $[27,28]$.

In recent years, there has been a downward trend in the observed PA levels for honey, herbal teas, and herbal food supplements ( $\bullet$ Table 1 ). This is likely the result of an array of measures, such as more rigorous quality controls, more widespread implementation of good agricultural practices, and instruction of the local producers. Such a decrease is not (yet) seen for pollen supplements and culinary herbs and spices. For the latter 2 commodities, this may be because the alerts of PA contamination are still relatively recent, and it may take some years before mitigation measures show their effects.

Taken all together, the reports on PA levels in food products have greatly increased public and regulatory awareness and have revealed the magnitude of the problem. Between 2012 and 2020, 76 notifications and alerts were posted on the EU RASFF portal, with 54 in the last 2 years. In the European Union, it has very recently resulted in a comprehensive legislative framework on PAs [34]. The new regulation specifies maximum levels for a set of 35 PAs in herbal and flavored teas, herbal food supplements, pollen-based supplements, borage, and culinary herbs and spices. The regulation will come into force on July 1,2022 , with a transitional period of 18 months for products placed on the market before that date. It is anticipated that the new regulatory framework will help to reduce further PA-contamination of food products consistent with the ALARA principle. The European Pharmacopeia [35] routine method foresees the analysis of 28 1,2-unsaturated PAs in herbal medicinal products.

\section{ADME Characteristics as Key Determinants in PA Toxicity}

Metabolism is well known to influence the toxicity of PAs since bioactivation is required for dehydro-PAs to become toxic. Although the metabolic pathway for bioactivation of the different PAs is similar, there are marked differences in metabolic clearance between different PAs, resulting in substantial differences in toxicity [36-38]. Other studies reported differences in the uptake of PAs across the intestinal barrier influencing relative differences in in vivo toxicity [39-41]. For example, the intestinal uptake of PA $\mathrm{N}$-oxides was reported to be less efficient than that of the corresponding PAs, contributing to the lower in vivo toxicity of the PA $\mathrm{N}$-oxides [39]. Furthermore, using a Caco-2 in vitro model, some $\mathrm{PAs}$ and $\mathrm{PA} \mathrm{N}$-oxides were shown to be taken up mainly via passive diffusion. In contrast, for others, active transporters appeared to be also involved [39]. Retronecine-type PAs, including monocrotaline and retrorsine, were shown to be high-affinity substrates of the organic cation transporter OCT1, indicating that OCT1 -mediated transport may contribute to their liver disposition and toxicity $[40,41]$. Thus, differences in PAs' ADME (absorption, distribution, metabolism, and excretion) characteristics exist that may substantially influence PA toxicity. This implies that when studying relative differences in PA toxicity using in vitro bioassays, potential differences in kinetics have to be taken into account before defining relative potency (REP) values for in vivo risk assessment of combined exposure. One way to consider these differences in ADME characteristics is so-called physiologically-based kinetic (PBK) modeling. PBK modeling can be applied to convert in vitro data on PA toxicity to the in vivo situation, taking differences in ADME characteristics into account by PBK modeling-facilitated reverse dosimetry ( $\bullet$ Fig. 2 ) $[37,42]$.

Proofs of principle for quantitative in vitro to in vivo extrapolation (QIVIVE) by PBK modeling-facilitated reverse dosimetry have been reported for liver toxicity and genotoxicity of some selected PAs [36, 37]. PBK modeling-facilitated reverse dosimetry was used to convert cytotoxicity data obtained for lasiocarpine and riddel- 
- Table 1 European studies and surveys on the detection of pyrrolizidine alkaloid residues in food products.

\begin{tabular}{|c|c|c|c|c|c|c|c|c|c|}
\hline $\begin{array}{l}\text { Product } \\
\text { group }\end{array}$ & Product & $\begin{array}{l}\text { No of PAs } \\
\text { analyzed }\end{array}$ & $\mathbf{N}$ & LC & $\begin{array}{l}\text { Mean } \\
(\mu \mathrm{g} / \mathrm{kg})\end{array}$ & $\begin{array}{l}\text { Median } \\
(\mu \mathrm{g} / \mathrm{kg})\end{array}$ & $\begin{array}{l}\text { P95 } \\
(\mu \mathrm{g} / \mathrm{kg})\end{array}$ & $\begin{array}{l}\text { Max } \\
(\mu \mathrm{g} / \mathrm{kg})\end{array}$ & Source \\
\hline \multirow[t]{3}{*}{ Salads } & (Mixed) rocket salada & 35 & 39 & $77 \%$ & 45 & $<\mathrm{LOQ}$ & 334 & 584 & NL survey, 2019d \\
\hline & Rocket salad ${ }^{a}$ & $21(35)^{b}$ & 17 & $76 \%$ & 9791 & $<\mathrm{LOQ}$ & $--^{c}$ & 166384 & \multirow[t]{2}{*}{ [23] } \\
\hline & Spinacha & $21(35)$ & 30 & $50 \%$ & 2.4 & 0.1 & - & 9.7 & \\
\hline \multirow{18}{*}{$\begin{array}{l}\text { Culinary } \\
\text { herbs }\end{array}$} & Various herbs & 35 & 50 & $36 \%$ & 617 & 19 & - & 10259 & NL survey, 2019d \\
\hline & Lovage & $21(35)$ & 22 & $18 \%$ & 1710 & 1073 & 6256 & 6256 & \multirow[t]{8}{*}[23,24]{} \\
\hline & Mugwort & $21(35)$ & 13 & $15 \%$ & 54 & 22 & - & 462 & \\
\hline & Oregano/marjoram & $21(35)$ & 95 & $9 \%$ & 4465 & 1484 & 18772 & 95234 & \\
\hline & Parsley & $21(35)$ & 41 & $54 \%$ & 222 & $<\mathrm{LOQ}$ & 1231 & 10893 & \\
\hline & Rosemary & $21(35)$ & 21 & $90 \%$ & 3.2 & $<\mathrm{LOQ}$ & 6.8 & 122 & \\
\hline & Thyme & $21(35)$ & 21 & $48 \%$ & 514 & 0.2 & 382 & 9565 & \\
\hline & Various herbs & $21(35)$ & 24 & $79 \%$ & 72 & $<\mathrm{LOQ}$ & 237 & - & \\
\hline & Mixed herbs & $21(35)$ & 68 & $24 \%$ & 648 & 86 & 3818 & 3818 & \\
\hline & Basil & 44 & 25 & $68 \%$ & 11 & $<\mathrm{LOQ}$ & 68 & 142 & \multirow[t]{9}{*}{ [25] } \\
\hline & Chives & 44 & 10 & $70 \%$ & 56 & $<\mathrm{LOQ}$ & - & 540 & \\
\hline & Dill & 44 & 17 & $65 \%$ & 52 & $<\mathrm{LOQ}$ & - & 681 & \\
\hline & Majoram & 44 & 31 & $3 \%$ & 58 & 24 & 152 & 524 & \\
\hline & Oregano & 44 & 24 & $13 \%$ & 3199 & 163 & 17021 & 24621 & \\
\hline & Parsley & 44 & 32 & $34 \%$ & 189 & 14 & 694 & 3297 & \\
\hline & Rosemary & 44 & 11 & $64 \%$ & 1.4 & $<\mathrm{LOQ}$ & - & 13 & \\
\hline & Savory & 44 & 29 & $21 \%$ & 150 & 7.0 & 799 & 1109 & \\
\hline & Thyme & 44 & 29 & $38 \%$ & 49 & 4.3 & 191 & 254 & \\
\hline \multirow{5}{*}{$\begin{array}{l}\text { Culinary } \\
\text { spices }\end{array}$} & Caraway & 44 & 20 & $65 \%$ & 0.6 & $<\mathrm{LOQ}$ & 2.4 & 8.5 & \multirow[t]{5}{*}{ [25] } \\
\hline & Cumin & 44 & 11 & $0 \%$ & 641 & 348 & - & 4307 & \\
\hline & Curry & 44 & 7 & $0 \%$ & 20 & 2.8 & - & 89 & \\
\hline & Ginger & 44 & 16 & $31 \%$ & 3.9 & 0.5 & - & 18 & \\
\hline & Pepper & 44 & 38 & $90 \%$ & 0.1 & $<\mathrm{LOQ}$ & 0.7 & 1.8 & \\
\hline \multirow{13}{*}{$\begin{array}{l}\text { Herbal } \\
\text { teas }\end{array}$} & Chamomile & 17 & 31 & $13 \%$ & 421 & 256 & 2556 & 3429 & \multirow[t]{4}{*}{ [26] } \\
\hline & Fennel & 17 & 30 & $43 \%$ & 48 & 1.4 & 528 & 904 & \\
\hline & Peppermint & 17 & 29 & $14 \%$ & 127 & 68 & 620 & 766 & \\
\hline & Mixed herbal & 17 & 42 & $12 \%$ & 137 & 25 & 771 & 1470 & \\
\hline & Black tea & 28 & 33 & $6 \%$ & 572 & 119 & 3620 & 4062 & \multirow[t]{6}{*}[27,28]{} \\
\hline & Green tea & 28 & 26 & $15 \%$ & 423 & 25 & 1472 & 3917 & \\
\hline & Chamomile & 28 & 35 & $14 \%$ & 274 & 125 & 1192 & 1394 & \\
\hline & Peppermint & 28 & 30 & $7 \%$ & 496 & 196 & 2990 & 4401 & \\
\hline & Rooibos & 28 & 22 & $5 \%$ & 599 & 244 & 1672 & 4805 & \\
\hline & Mixed herbal & 28 & 20 & $5 \%$ & 439 & 180 & 1800 & 1929 & \\
\hline & Green tea & 30 & 38 & $16 \%$ & 140 & 2.7 & 236 & 4246 & \multirow[t]{3}{*}{ [29] } \\
\hline & Black tea & 30 & 39 & $13 \%$ & 43 & 2.3 & 257 & 887 & \\
\hline & $\begin{array}{l}\text { Herbal tea, } \\
\text { rooibos tea }\end{array}$ & 30 & $76^{e}$ & $11 \%$ & 129 & 21 & 902 & 1936 & \\
\hline
\end{tabular}


- Table 1 Continued

\begin{tabular}{|c|c|c|c|c|c|c|c|c|c|}
\hline $\begin{array}{l}\text { Product } \\
\text { group }\end{array}$ & Product & $\begin{array}{l}\text { No of PAs } \\
\text { analyzed }\end{array}$ & $\mathbf{N}$ & LC & $\begin{array}{l}\text { Mean } \\
(\mu \mathrm{g} / \mathrm{kg})\end{array}$ & $\begin{array}{l}\text { Median } \\
(\mu g / k g)\end{array}$ & $\begin{array}{l}\text { P95 } \\
(\mu \mathrm{g} / \mathrm{kg})\end{array}$ & $\begin{array}{l}\text { Max } \\
(\mu g / k g)\end{array}$ & Source \\
\hline & Black tea & $21(35)$ & 111 & $45 \%$ & 12 & 1 & 65 & - & \multirow[t]{8}{*}{ [23] } \\
\hline & Green tea & $21(35)$ & 98 & $64 \%$ & 8.0 & $<\mathrm{LOQ}$ & 37 & - & \\
\hline & Chamomile & $21(35)$ & 84 & $32 \%$ & 29 & 8.7 & 120 & - & \\
\hline & Fennel tea & $21(35)$ & 101 & $57 \%$ & 6.6 & $<\mathrm{LOQ}$ & 22 & - & \\
\hline & Peppermint & $21(35)$ & 122 & $53 \%$ & 34 & $<L O Q$ & 105 & - & \\
\hline & Rooibos & $21(35)$ & 175 & $11 \%$ & 107 & 38 & 494 & - & \\
\hline & Mixed herbal & $21(35)$ & 229 & $27 \%$ & 97 & 15 & 410 & - & \\
\hline & Tea for children & $21(35)$ & 28 & $43 \%$ & 37 & 0.3 & 92 & - & \\
\hline \multirow{4}{*}{$\begin{array}{l}\text { Herbal } \\
\text { supple- } \\
\text { ments }\end{array}$} & Various & 28 & 107 & $37 \%$ & 318 & 11.4 & - & 8488 & {$[27,28]$} \\
\hline & St. Johns wort & 35 & 48 & $10 \%$ & 969 & 274 & 4576 & 5221 & NL survey, $2018^{\circ}$ \\
\hline & Various & $21(35)$ & 61 & $44 \%$ & 39 & 0.3 & - & 125 & [23] \\
\hline & Various & 44 & 50 & $62 \%$ & 6.1 & $<L O Q$ & - & 105 & [30] \\
\hline \multirow{6}{*}{$\begin{array}{l}\text { Pollen } \\
\text { supple- } \\
\text { ments }\end{array}$} & Pollen & 17 & 119 & $40 \%$ & $(1846)^{f}$ & $(192)^{f}$ & - & 37,855 & {$[5]$} \\
\hline & Pollen-based & 28 & 29 & - & 243 & 4.8 & - & - & {$[27,28]$} \\
\hline & Pollen-based & 28 & 41 & - & 235 & - & 967 (P90) & - & {$[6]$} \\
\hline & Pollen & 18 & 32 & $69 \%$ & 100 & $<\mathrm{LOQ}$ & - & 1185 & [31] \\
\hline & Pollen & $21(35)$ & 18 & $6 \%$ & 721 & 125 & - & 5083 & {$[23]$} \\
\hline & Beehive products & 30 & 23 & $26 \%$ & 4.4 & 0.9 & 26 & 43 & [32] \\
\hline \multirow[t]{6}{*}{ Honey } & Retail honey & 8 & 1324 & $10 \%$ & 16 & 10 & 57 & 169 & [5] \\
\hline & Retail honey ${ }^{g}$ & $8-19$ & 1966 & - & $14-15$ & $0-8$ & $18-55$ & - & [6] \\
\hline & Retail honey & 28 & 129 & - & 11 & 2.1 & 40 & - & [33] \\
\hline & Retail honey & $21(35)$ & 244 & $56 \%$ & 3.0 & $<\mathrm{LOQ}$ & 18 & - & [23] \\
\hline & Retail honey h & 30 & 116 & $9 \%$ & 6.6 & 1.0 & 19 & 182 & \multirow[t]{2}{*}{ [32] } \\
\hline & Retail honey ${ }^{i}$ & 30 & 374 & $33 \%$ & 1.1 & 0.14 & 4.3 & 61 & \\
\hline $\begin{array}{l}\text { Dairy } \\
\text { products }\end{array}$ & Milk & 35 & 182 & $94 \%$ & $<0.01$ & $<L O Q$ & 0.06 & 0.17 & {$[27,28]$} \\
\hline \multicolumn{10}{|c|}{ 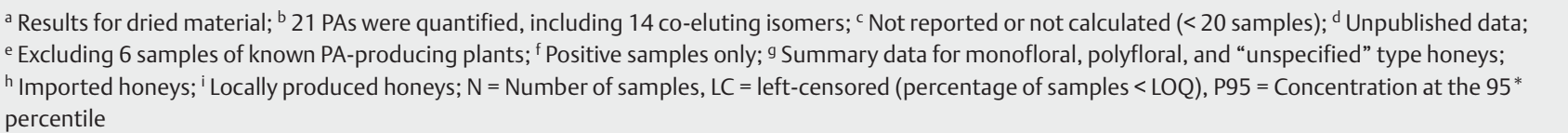 } \\
\hline
\end{tabular}

liine in hepatocytes in vitro to predict in vivo acute liver toxicity of these PAs in rats and humans [36,37]. While the difference in toxicity observed in the in vitro studies with rat hepatocytes was 1.7 fold, with riddelliine being more toxic than lasiocarpine, the difference in the predicted in vivo toxicity was substantially higher, amounting to 2.7-7-fold [36]. The relatively higher in vivo than in vitro toxicity of riddelliine compared to lasiocarpine was ascribed by Chen et al. [36] to the slower metabolic clearance of riddelliine. In another study, substantial differences in in vitro clearance of a series of PAs in incubations with a rat sandwich culture hepatocyte cell system were reported [38]. The relative differences in the hepatic in vitro clearance varied with the PA concentration tested in this study. An observation that can be taken into account in PBK modeling by including the kinetic parameters Vmax and $\mathrm{Km}$ for the respective clearance in the model code. In a QIVIVE study on the monocrotaline-induced liver toxicity in rats predicted by a PBK modeling-facilitated reverse dosimetry, the role of the OCT1 transporter was taken into account, providing a proof of principle on how to deal with differences in PA absorption [43].

Given that in vivo data are available for only a limited number of the 1,2-unsaturated PAs and PA N-oxides considered relevant for food and feed, ways to adequately translate in vitro toxicity data to the in vivo situation, taking differences in kinetics into account, are urgently required. This also holds true for the PA $\mathrm{N}$-oxides, which appear to be the form in which the PAs may occur, sometimes exclusively, in many botanicals and botanical preparations 

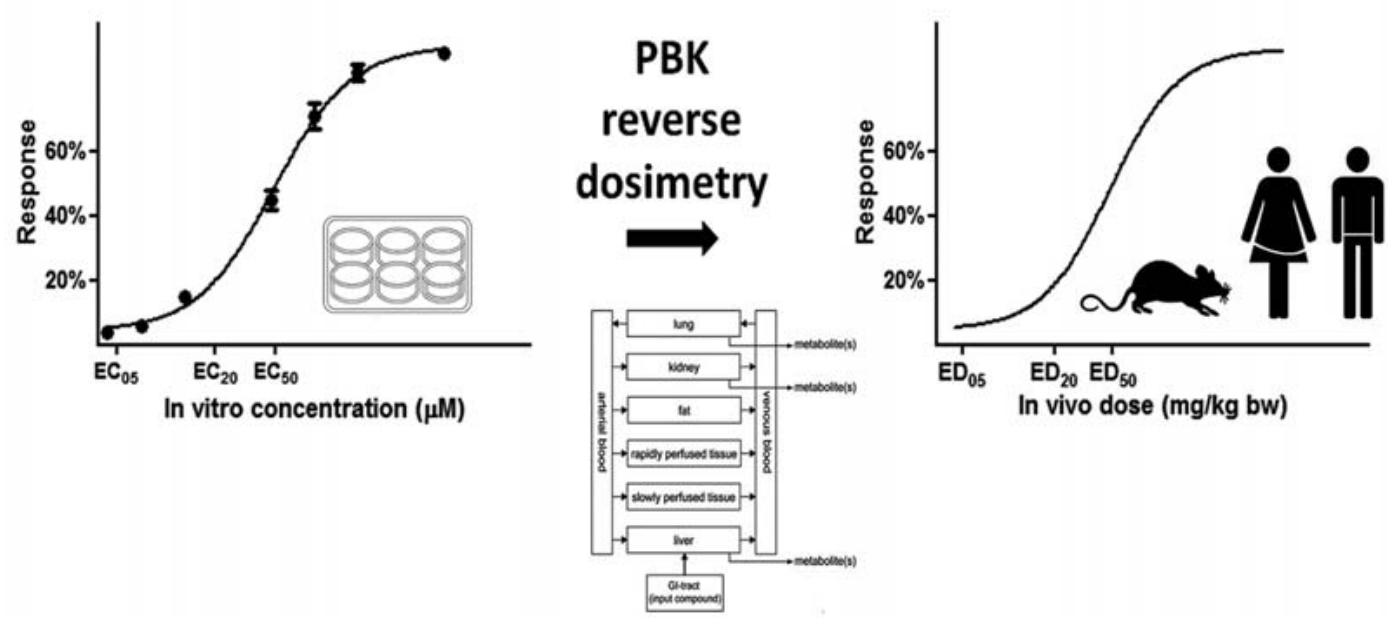

- Fig. 2 The principle of PBK modeling-facilitated reverse dosimetry to take kinetics into account when translating in vitro concentration-response curves for toxicity to in vivo dose-response curves in quantitative in vitro to in vivo extrapolation (QIVIVE).

[44]. The in vivo toxicity of PA $\mathrm{N}$-oxides depends on their reduction to PAs by intestinal microbiota and to a lesser extent in liver and intestinal tissue. The intestinal microbiota appears to play the most important role in this reduction $[18,19]$. A first proof of principle to include metabolism by the intestinal microbiota in PBK models has been provided [45], and similar studies are currently performed for PA $\mathrm{N}$-oxides. In these studies, kinetic parameters to describe the intestinal metabolism of the compounds of interest in the PBK model are obtained using anaerobic fecal incubations. Initial PBK studies on riddelliine $\mathrm{N}$-oxide as the model compound revealed that the plasma-concentration time curve would show lower maximal plasma concentrations for the parent PA riddelliine (Cmax) and a longer time to reach these values (Tmax) than what is observed upon oral dosing of riddelliine itself. This result is in line with what has been reported in rats using PA or PA N-oxide containing Gynura alkaloid extracts [39].

It is concluded that ADME characteristics are key determinants in PA toxicity and that definition of REP values should take differences in these kinetics between the PAs and also their PA $\mathrm{N}$-oxides into account.

\section{Identification and Quantification of PA Metabolites: Consequences for Risk Assessment}

Since more than 6000 plants over 300 plant species of up to 13 families can produce PAs, hundreds of different individual structures occur naturally. For exposure assessment, it is important to know to what extent the applied targeted methods, which have a limited analytical scope compared to the high number of naturally occurring PAs, cover the total PA content. In addition, the knowledge of detailed PA profiles to which consumers are exposed could be of interest if a differentiated toxicological assess-

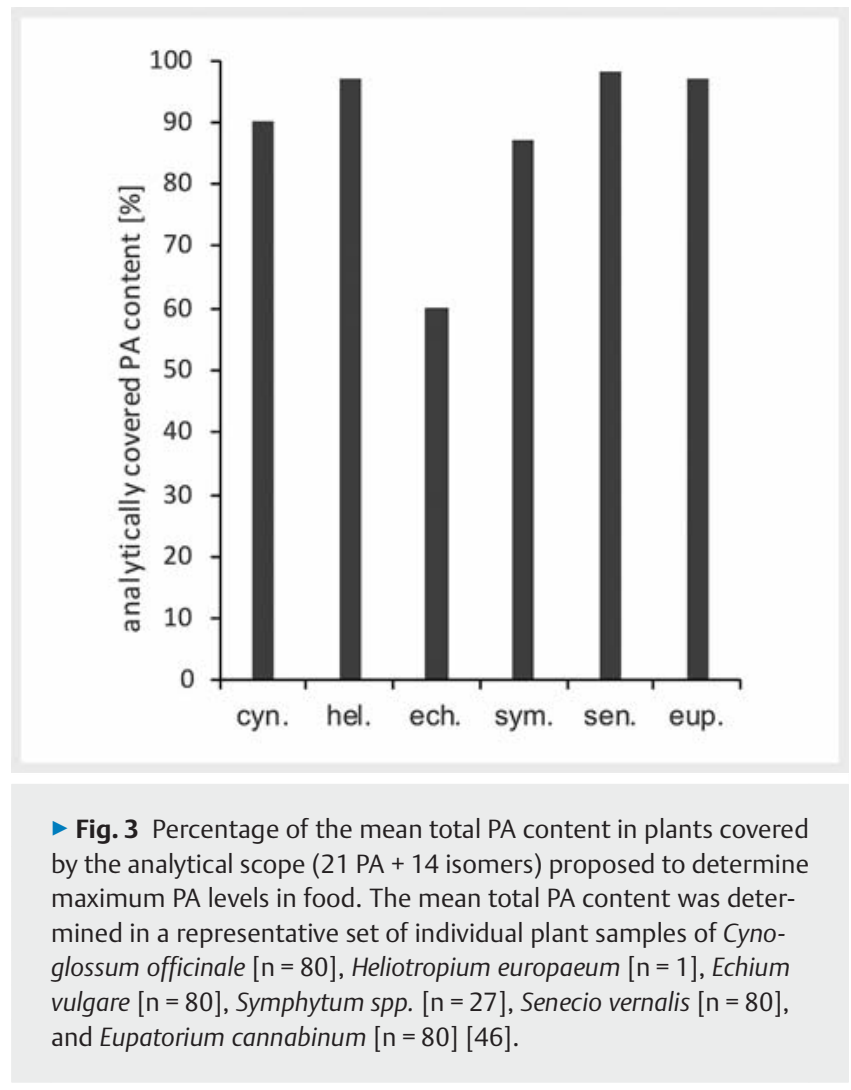

ment of the individual PAs would be established. Using mass spectrometry, individual PAs of all relevant necine base structures like the 1,2-unsaturated retronecine, heliotridine, and supinidine types and the 1,2-saturated platynecine and trachelanthamidine type in plants were identified and quantified, whether these individual PAs were known or unknown [46]. Based on these results, typical profiles in PA-producing plants were characterized. It was 


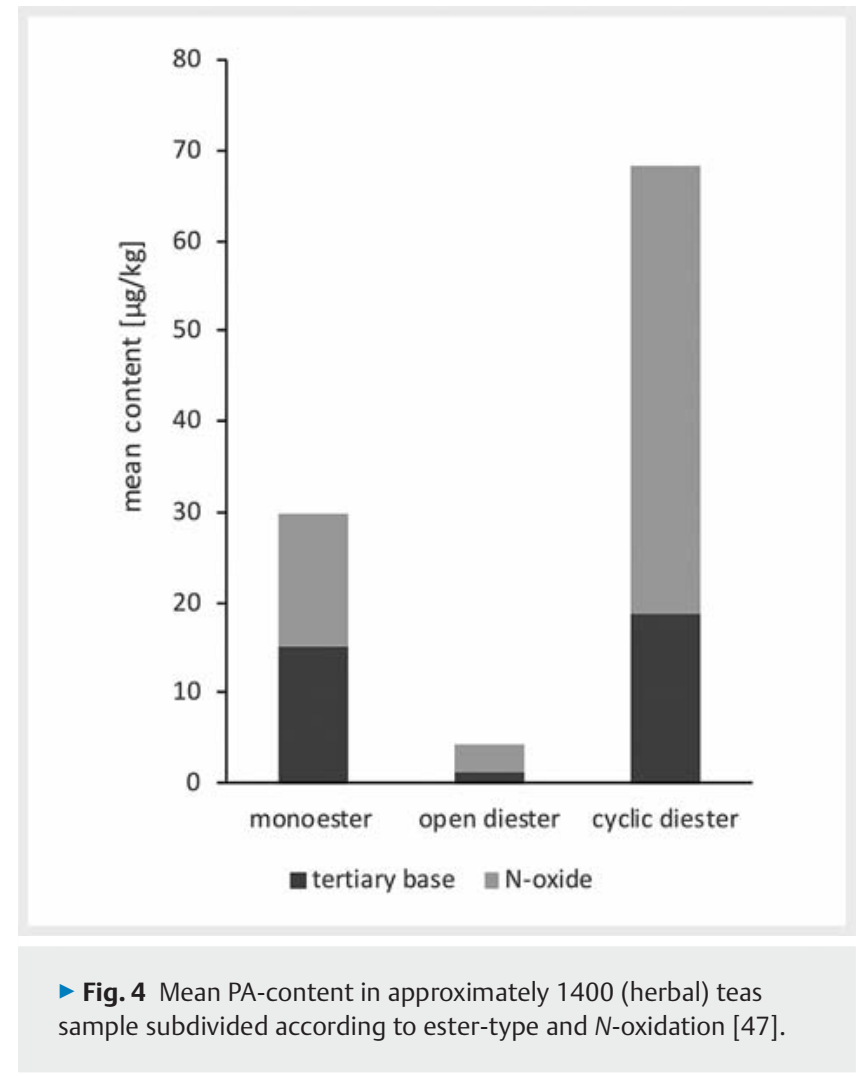

shown that a) around $90 \%$ of PAs in plants are present as $\mathrm{N}$-oxides and b) the 1,2-unsaturated retronecine and heliotridine necine base PAs play a dominant role while saturated forms only present minor alkaloids. Further, it was shown that only a few marker alkaloids account for the majority of the total PA content.

The proposed analytical scope for determining maximum levels (21 PAs +14 of their isomers) covered the substantial contributors to the total PA content, including the relevant marker PAs ( $\vee$ Fig. 3). Consequently, the results of food analysis were used to obtain knowledge of PA profiles to which consumers are exposed. As shown in $>$ Fig. 4 , the $\mathrm{N}$-oxide forms of monoesters and cyclic diesters account for the highest proportion of PA exposure [47]. Subsequently, hepatic PA metabolism was investigated using rat and human liver microsomal preparations $[48,49]$. If the results were focused on metabolic transformation of the parent PA, there was a trend toward higher transformation rates in rat liver microsomes compared to humans, where especially for monoesters, no metabolic degradation was found. The detection of glutathioneDHP conjugates, metabolites considered as an indirect measure of toxicity, revealed a high congruence between both species. In terms of PA structures, the highest levels were detected for 1,2 unsaturated retronecine or heliotridine diesters with angelic acid at C7 regardless of whether the diesters are open or cyclic [48]. For 6 selected PAs, a comprehensive metabolite profile study was performed, and between 5 metabolites for europine and up to 48 metabolites for lasiocarpine were detected [49]. For each metabolite, potential structures were proposed based on high-resolution mass spectrometry fragmentation patterns. According to these structure proposals, the metabolites were grouped, basi- cally into i) reactive metabolites bioactivated in the necine base moiety (dehydrogenated pyrrolic compounds, including glutathione-DHP conjugates, or pyrrole-like metabolites carbon-oxygenated in the necine base) or ii) other metabolites ( $\mathrm{N}$-oxides and compounds that are modified in the necic acid moiety by, for example, hydroxylation, epoxidation or dealkylation). While the formation of reactive metabolites is considered toxification, the other transformation steps are considered pathways leading to detoxification. While almost none of these bioactivated metabolites were detected in incubations of monoesters, all diesters investigated were metabolized to such products, with lasiocarpine forming the highest number and amount of such reactive metabolites [49].

\section{Pathways Leading to DNA Adduct Formation and Potential Liver Tumor Initiation}

Recently a set of ( \pm )-6,7-dihydro-7-hydroxy-1-hydroxymethyl-5Hpyrrolizine (DHP)-DNA adducts, designated as DHP-dG-3, DHP-dG-4, DHP-dA-3, and DHP-dA-4, was identified that lead to

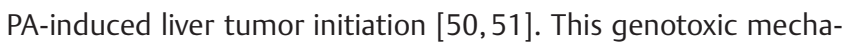
nism is involved in the metabolism of a series of hepatocarcinogenic PAs and PA N-oxides in rats in vivo [52]. There is a correlation between the order of liver tumor potency and the level of DHPderived DNA adduct formation [51,52], and these DHP-DNA adducts can be potential biomarkers of PA and PA $N$-oxide exposure and liver tumor initiation [52].

Previously, dehydro-PAs and DHP were the only metabolites that have been shown to bind to cellular DNA to form DHP-DNA adducts and cause liver tumor initiation $[50,52]$. Other metabolites may exist that can cause the same set of DHP-DNA adducts. In 2015, it was found that 7-glutathione-DHP (7-GS-DHP) ( $\vee$ Fig. 5 a), a secondary pyrrolic metabolite, is DNA-reactive and forms these DHP-DNA adducts [52]. It was also observed that both 7-cysteine-DHP (7-CYS-DHP) and 7- N-acetylcystyeine-DHP (7-NAC-DHP) are DNA-reactive [52]. Similarly, in 2019, it was reported that 1-formyl-7-hydroxy-6,7-dihydro-5H-pyrrolizine (1CHO-DHP), 9-valine-DHP, and 7-methoxy-DHP are DNA-reactive in HepG2 cells $[53,54]$. Incubation of $1-\mathrm{CHO}-\mathrm{DHP}$ with HepG2 cells with cysteine formed 3 DNA-reactive metabolites-cysteinyl[2'-S-7]-1-CHO-DHP (P2), cysteinyl-[3'-N-7]-1-CHO-DHP (P3), and 1-cysteinylimino-DHP (P5) ( $\mathbf{F i g} .5$ a) [55]. Thus, there are currently 10 identified secondary pyrrolic metabolites that are DNA-reactive ( $\bullet$ Fig. 5 a) and capable of binding to cellular DNA to produce DHP-dG-3, DHP-dG-4, DHP-dA-3, and DHP-dA-4, which can potentially lead to PA-induced liver tumor initiation ( Fig. 5b).

There may be many yet-to-be-identified DNA-reactive secondary pyrrolic metabolites. Metabolism of secondary pyrrolic metabolites may lead to liver tumor initiation mediated by DHP-DNA adduct formation. DNA-reactive pyrrolic metabolites are unique in that they are all bifunctional alkylating agents, capable of binding to nucleophilic sites (-SH, - $\mathrm{NH}$, and $\mathrm{OH}$ groups) on the surrounding amino acids, proteins, and DNA, etc. Products resulting from these reactions are also highly reactive, possessing bifunctional alkylating activity undergoing reactions with nearby biochemicals 
<smiles>OCc1ccn2c1[C@H](O)CC2</smiles><smiles>O=CCc1ccn2c1[C@H](O)CC2</smiles>

1-CHO-DHP<smiles>OCc1ccn2c1[C@H](S)CC2</smiles>

7-GS-DHP<smiles>OCc1ccn2c1[C@H](S[As])CC2</smiles>

7-CYS-DHP<smiles>N#CC1CCn2ccc(CO)c21</smiles>

7-NAC-DHP<smiles>CO[C@@H]1CCn2ccc(CO)c21</smiles>

7-Methoxy-DHP<smiles>NC(O)(O)CSC1CCn2ccc(CC=O)c21</smiles>

Cysteinyl-[2'-S-7] -1-CHO-DHP(P2)<smiles>CCc1ccn2c1C(NC(S)C(=O)O)CC2</smiles>

Cysteinyl-[3'-N-7] -1-CHO-DHP(P3)<smiles>O=C(O)C(CS)N=Cc1ccn2c1C(O)CC2</smiles>

1-Cysteinylimino -DHP (P5)<smiles>CC(C)C(NCc1ccn2c1[C@H](O)C[C@@H](O)[C@H]2O)C(=O)O</smiles><smiles>[R]CCC(=O)OCC1=CCN2CC[C@H]3OC(=O)CC[C@@H]1[C@@H]32</smiles>

PA<smiles>[R]CCC(=O)OCc1ccn2c1[C@H](OC(=O)CC)CC2</smiles>

DHP esters

(Dehydro-PA)

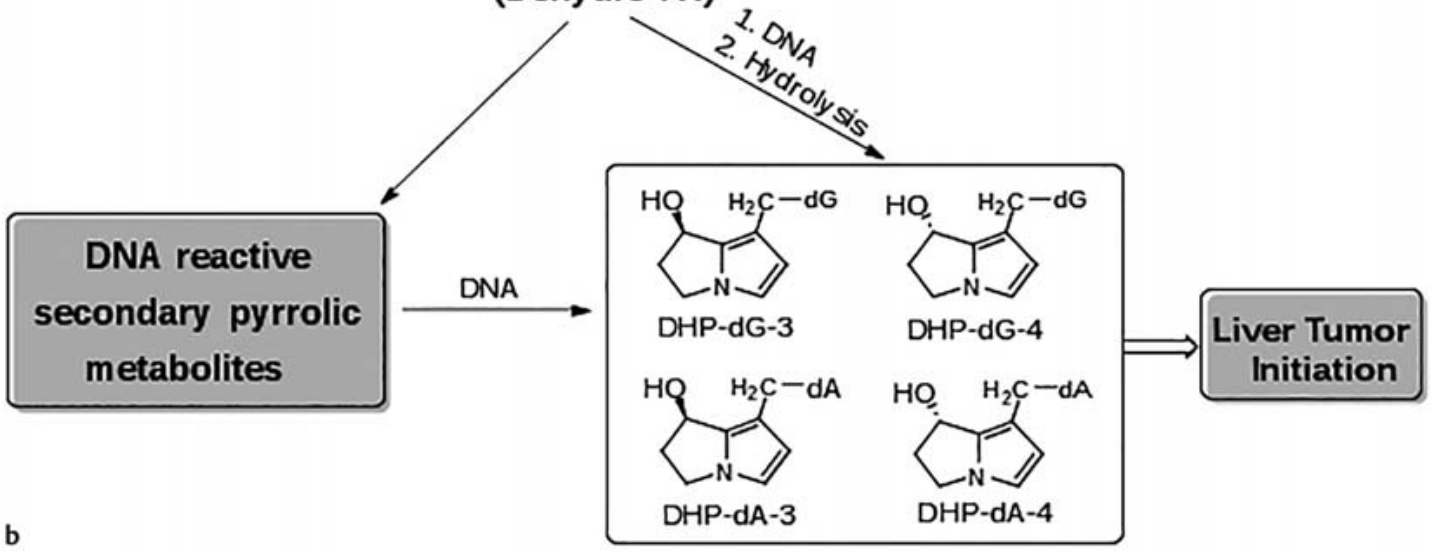

- Fig. 5 (a) DNA-reactive pyrrolic metabolites and (b) proposed genotoxic mechanism mediated by multiple secondary pyrrolic metabolites that lead to DHP-DNA adduct formation and PA-induced liver tumor initiation.

to yield products that also exhibit this bifunctional alkylating characteristic. Specifically, the 5 DNA-reactive secondary pyrrolic metabolites-DHP, 7-GS-DHP, 7-CYS-DHP, 7-NAC-DHP, and 1CHO-DHP-have been found to be highly abundant and are commonly formed from the metabolism of PAs and PA $\mathrm{N}$-oxides in vitro. Thus, their activities require further investigation to understand their potential role in liver cancer development.

In conclusion, a series of DNA-reactive secondary pyrrolic metabolites was identified that construct multiple activation pathways potentially leading to liver tumor initiation; each pathway generates the same set of 4 DHP-DNA adducts ( $\bullet \mathbf{F i g} \cdot \mathbf{5} \mathbf{b}$ ). The findings suggest that DNA-reactive secondary pyrrolic metabolites may play a vital role in initiating PA-induced liver tumors.

\section{Application of Cutting-Edge Research Tools to PA Risk Assessment}

Since the liver is the main target organ for PA toxicity, in vitro investigations have been conducted and used to parameterize PBK models to predict liver concentrations following oral exposures. The preliminary results of the impact of intestinal absorption and metabolism on potency rankings of PAs were presented at the PAeSymposium, September 2020.

Specifically, a series of PAs and their respective $\mathrm{N}$-oxides were examined for their ability to undergo pre-systemic metabolism and intestinal absorption following oral ingestion. These data were used to parameterize a human PBK model (based on PK-Sim: http://www.open-systems-pharmacology.org), and simulations 

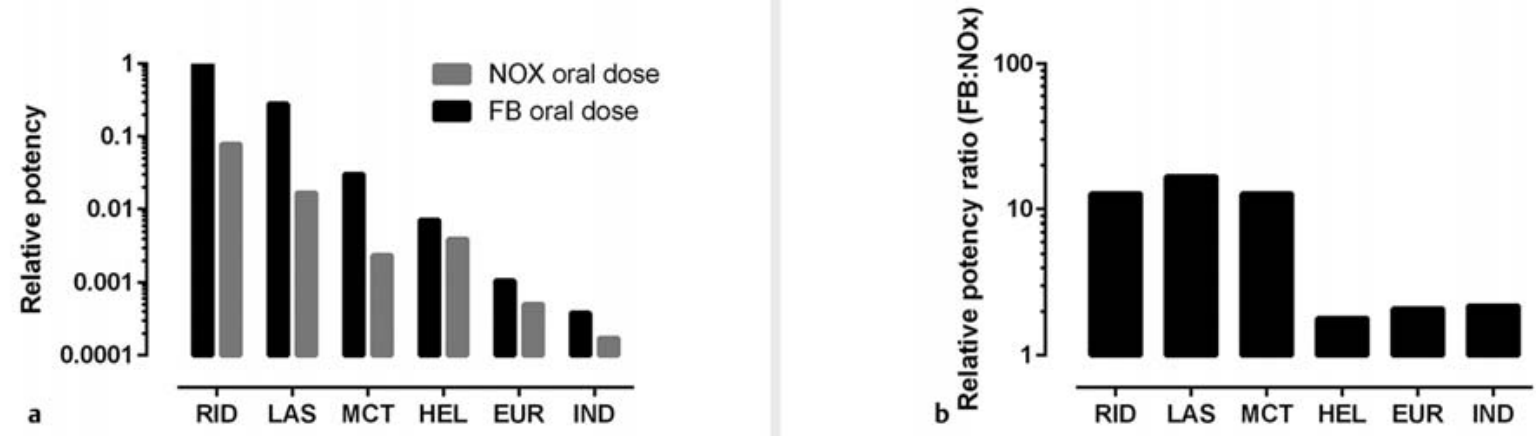

Fig. 6 Preliminary oral potency differences of PA and representative $N$-oxides informed through PBK modeling (a) and the ratio of relative ora potency for 6 pairs of PA: PA N-oxide (b). The abbreviations stand for riddelliine (RID), lasiocarpine (LAS), monocrotaline (MCT), heliotrine (HEL), europine (EUR), and indicine (IND), free base (FB), N-oxide (NOx).

performed to derive PA concentration-time profiles and area under the curve (AUC) values in liver tissue. PBK-derived liver AUC values were multiplied by PA-specific DNA adduct formation scaling factors previously determined using in vitro rat sandwich cultured hepatocytes to estimate the in vivo DNA adduct formation in human liver tissue [38]. There, the measured DNA adduct formation relative to the AUC of parent PA in extracellular media (adducts/AUC) provided a measure of the intrinsic hepatic potency of each PA, thus providing an estimate of expected liver DNA adduct formation and relative potency for PA risk assessment. Importantly, DNA adduct formation was observed to be linear concerning the AUC of parent PA in extracellular media at in vitro PA dose concentrations ranging from 10 to $100 \mu \mathrm{M}$. Therefore, these values can serve as in vitro to in vivo scaling factors combined with PBK-derived liver AUC predictions to estimate the DNA adduct formation expected to occur under low concentrations, thus measuring relative potency. This pragmatic approach addresses the challenge of considerably lower physiologic concentrations of PAs and/or low potency PAs for which measurement of DNA adducts would be beyond the limits of analytical detection. Albeit this linear extrapolation is a conservative assumption, given the likely DNA repair processes that play a role at low concentrations when in vitro derived potency values (adducts/ AUC) are multiplied by the PBK model-predicted liver AUCs, potency rankings that take account of both kinetic and dynamic aspects can be inferred.

Using this PBK modeling approach, preliminary potency differences spanning 3 orders of magnitude were observed following an oral dose of the free base, with diesters riddelliine, lasiocarpine, and monocrotaline seen as more potent than monoesters heliotrine, europine, and indicine ( $\boldsymbol{F}$ Fig. $\mathbf{6 a}$ ). Following an oral dose of the $\mathrm{N}$-oxide, the rank order of relative potency was similar to free base oral dosing except for the potency ranking of heliotrine $\mathrm{N}$-oxide being slightly higher than monocrotaline $\mathrm{N}$-oxide. When comparing oral doses of the free base and $\mathrm{N}$-oxides, the $\mathrm{N}$-oxides were predicted to be 10 -fold (diesters) and 2-fold (monoesters) less potent than their respective free base ( $\bullet$ Fig. $\mathbf{6} \mathbf{b}$ ).
In these preliminary PBK model predictions ( $\vee$ Fig. 6 a), the potency of riddelliine was shown to be greater than that of lasiocarpine. Although initially surprising, this is perhaps best explained by the rate and extent of PA metabolism. In previous investigations [38] with plated rat liver cells, lasiocarpine exhibited a rapid depletion rate and correspondingly lower AUC than the slower depletion rate and consequently greater AUC for riddelliine. Similarly, the PBK model predictions reveal a greater liver AUC for riddelliine than other PAs (data not shown), which likely explains the observed higher overall potency. Similar findings were reported by Chen et al. [56], who also used a PBK modeling approach to predict in vivo genotoxicity of lasiocarpine and riddelliine.

Although these rankings should be viewed only as preliminary findings from a provisional PBK model, the potency differences are starting to be informed by in vitro toxicokinetics data (Troutman, manuscript in preparation). Consistent with the trends reported by Yang et al. [39], Caco-2 permeability measurements show that $\mathrm{N}$-oxides and monoesters exhibit low permeability. In contrast, representative diesters lasiocarpine, riddelliine, and monocrotaline have moderate gut permeability. Moreover, while $\mathrm{N}$-oxides are not readily absorbed, they are converted to the free base by gut microbiota. We have observed the formation rate to follow a similar trend with diesters > monoesters. Lastly, the major site for PA metabolism appears to be the liver, with substantial losses detected in incubations with liver microsomes and negligible losses observed in incubations with intestinal microsomes.

In conclusion, in vitro kinetic data reveal that metabolism in the liver and by intestinal microbiota are the 2 major determinants of the metabolic transformation of PA and their $\mathrm{N}$-oxides, respectively. Together with uptake from the gastrointestinal tract, these are key contributors to PA kinetics and thus impact potency. Altogether, the data suggest that the provisional potency factors also proposed by Merz and Schrenk for PA $\mathrm{N}$-oxides appear to be rather conservative. 


\section{Dose-Response Curves in Alkylation-Induced Genotoxicity and Their Implications for PAs}

PAs undergo metabolic activation catalyzed by CYP450 monooxygenases, resulting in DNA adducts and DNA-protein crosslinks [57]. An important issue is the relative genotoxic potency of these structurally diverse compounds and their dose-response curve. In this context, it is worth having a closer look at $\mathrm{N}$-nitroso compounds (NOC). NOC are an important group of heat-induced genotoxic food contaminants that also arise endogenously in the human gastrointestinal tract [58]. NOC are harmful $\mathrm{S}_{N} 1$-alkylating agents that lead to various DNA adducts, such as $\mathrm{N}$-methylated purine bases and $O^{6}$-Methylguanine $\left(O^{6}-\mathrm{MeG}\right) . O^{6}-\mathrm{MeG}$ is a cytotoxic and highly mutagenic lesion causally linked to colorectal carcinogenesis [59]. This DNA adduct is specifically repaired by $0^{6}$ methylguanine DNA-methyltransferase (MGMT) in a 1-step reaction, leading to the restoration of guanine in DNA and MGMT degradation [60]. The dose-response relationship of NOC-induced DNA alkylation and colorectal cancer (CRC) formation was studied extensively in recent years. Furthermore, it was analyzed how relevant DNA repair pathways affect the dose-response curve using genetic models in vivo. These findings demonstrated for the first time that DNA repair competent wild-type (WT) mice show a nonlinear dose-response in NOC-induced CRC formation. In contrast, mice deficient for MGMT displayed a linear dose-response in CRC formation [61]. Intriguingly, the NOC-induced levels of the DNA damage marker $\mathrm{y}$ - $\mathrm{H} 2 \mathrm{AX}$ detected in colorectal tissue correlated very well with the observed dose-response in CRC formation [61]. Furthermore, mass spectrometry-based analysis revealed a nonlinear formation of $\mathrm{O}^{6}$-MeG adducts in colorectal tissue of NOC-treated WT mice, which is in line with the later tumor formation [62]. In contrast, MGMT knockout mice showed a linear NOCtriggered $\mathrm{O}^{6}$-MeG formation, highlighting the pivotal role of MGMT-mediated repair [62]. These data were instrumental in determining genotoxic and carcinogenic points of departure in WT mice using the hockey-stick dose-response modeling [63] which were absent in MGMT-deficient mice [61,62].

In recent years, several studies investigated the concentrationresponse curve of PA-triggered genotoxicity using cell culture models. The obtained data for micronuclei or $y$-H2AX formation were then subjected to benchmark concentration (BMC) modeling. A very recent study in CYP3A4-expressing HepG2 cells found hypo-linearity in micronuclei induction for the cyclic diesters senecionine and retrorsine. In contrast, the open diester lasiocarpine displayed linear concentration-dependent micronuclei formation [64]. The BMC for a $100 \%$ increase of micronuclei over control $\left(\mathrm{BMC}_{1}\right)$ was found to be $0.04 \mu \mathrm{M}$ for lasiocarpine, while it was higher for senecionine and retrorsine $(0.1 \mu \mathrm{M}$ and $1.3 \mu \mathrm{M}$, respectively) [64]. Another work in HepaRG cells showed a rather hypolinear concentration-response curve for both lasiocarpine and retrorsine. However, it confirmed the higher potency of lasiocarpine compared to retrorsine with a $\mathrm{BMC}_{1}$ of $1 \mu \mathrm{M}$ versus $10 \mu \mathrm{M}$ [65]. Preliminary studies lend support for a linear concentration-response curve in lasiocarpine-triggered $\gamma$ - $\mathrm{H} 2 \mathrm{AX}$ formation using HepG2-CYP3A cells. Further concentration-response studies considering the lower concentration range and further endpoints (e.g., DNA strand break induction) are warranted. Furthermore, it is tempting to speculate that DNA repair pathways, as reported in the case of DNA alkylation damage, may affect the concentrationresponse curve in PA-induced genotoxicity.

\section{Structure-Dependent Genotoxic Potencies of Selected PAs in Primary Hepatocytes and Liver Cell Lines}

In 2016, Merz and Schrenk [17] derived iREP factors for 15 PA congeners and $3 \mathrm{~N}$-oxides. The provisional assignment of factors to PAs was based on their combined genotoxic potency in Drosophila, cytotoxic potency in vitro, and acute toxicity in adult rodents. The analysis revealed a structure-toxicity relationship influenced by the type of esterification (monoester, open diester, cyclic diester), and to some extent, by the stereochemistry of the carbon atom $C 7$ (7S or 7R).

Chronic liver damage and liver tumor formation have to be considered as critical endpoints. It is supposed that such exposure may eventually lead to these endpoints in a time- and dose-dependent manner. However, sub-chronic or chronic animal experiments with a relevant number of congeners to explore the doseresponse relationships are not feasible because of the "reduce-refine-replace" (3R)-principles [66].

Thus, relevant in vitro models remain a major source of additional information. These should comprise models for genotoxicity, metabolism, and toxicokinetics. Such data may be used to model internal exposure and the resulting risk, as well as structure-potency and mode-of-action studies.

Allemang et al. [65] treated human HepaRG cells for $24 \mathrm{~h}$ with various congeners and measured micronuclei using flow cytometry. Fifteen congeners (comprising $3 \mathrm{~N}$-oxides) belonging to 6 different sub-classes were tested. The concentration-response curves were used for BMC calculations using a doubling of micronuclei over the background as a benchmarking effect. A structuredependent diverse pattern of genotoxic potencies was obtained with lower bound concentrations spanning about $1 \mu \mathrm{M}$ to almost $300 \mu \mathrm{M}$, with all $3 \mathrm{~N}$-oxides being much less potent.

Lester et al. [38] incubated rat hepatocytes in sandwich culture over 6 and $24 \mathrm{~h}$ with various concentrations of 9 different PAs. They determined the levels of DHP-DNA adducts at adenine and guanine and the metabolic rate in culture (AUC). The ratio adducts/AUC was considered a biomarker of hepatocyte exposure to DNA binding metabolites and used as a parameter for the intrinsic potency of each congener varying between 0.08 and 1.0, with lasiocarpine being the most potent congener. Furthermore, monocrotaline was one of the congeners with the highest AUC, lasiocarpine with the smallest.

Louisse et al. [67] used the $\gamma \mathrm{H} 2 \mathrm{AX}$ level (50\% increase) in a western assay in HepaRG human liver cells to determine the concentration-dependent genotoxicity of 37 PAs, 36 of them representing different chemical sub-groups of the 1,2-unsaturated PAs. Several open diesters and cyclic diesters (except monocrotaline) were found among the most potent genotoxicants. The least 


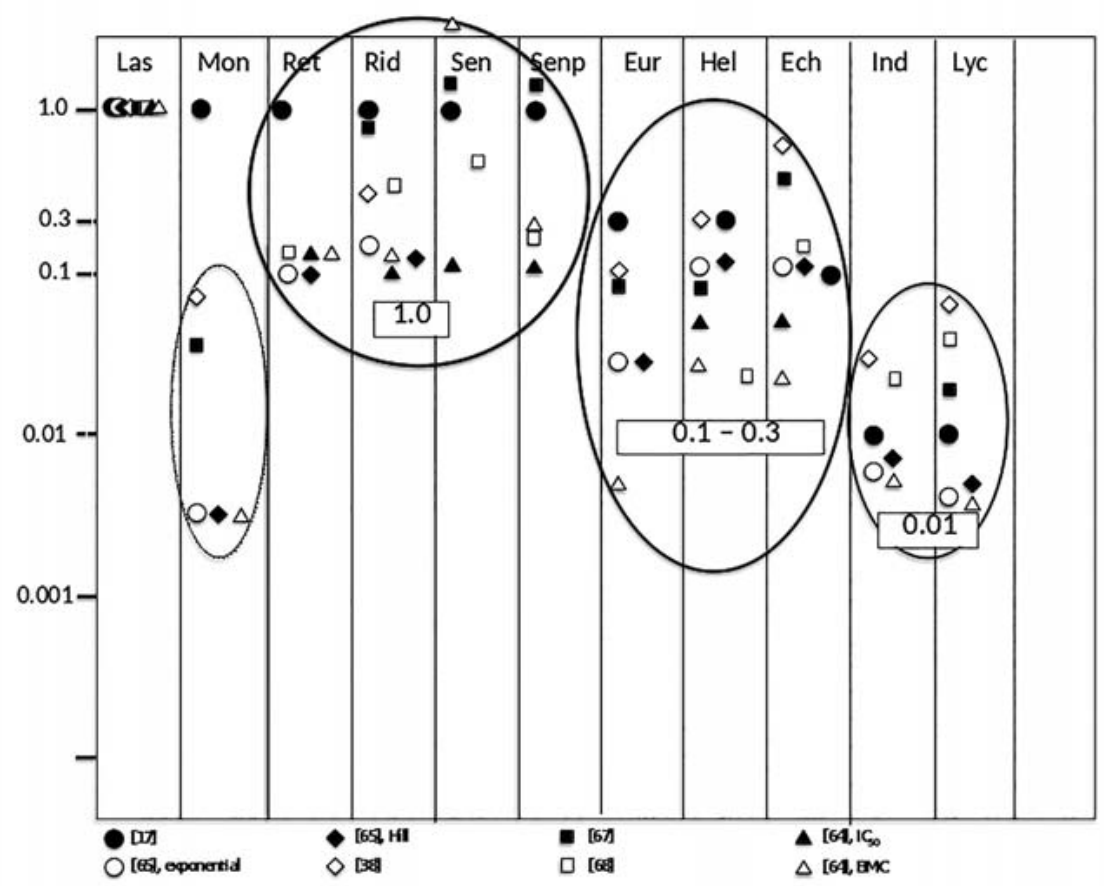

- Fig. 7 Overview over iREP factors as suggested by Merz and Schrenk [17] for certain PAs together with relative potencies derived from in vitro studies on cyto- or genotoxicity as indicated by reference numbers. $I C_{50}=$ concentration at half-maximal inhibition of cell vitality; $B M C=$ benchmark concentration. The abbreviations stand for lasiocarpine (Las), monocrotaline (Mon), retrorsine (Ret), riddelliine (RID), senecionine (Sen), seneciphylline (Senp), europine (Eur), heliotrine (Hel), echimidine (Ech), indicine (IND) and lycopsamine (Lyc). The congeners are listed alphabetically, according to decreasing iREP factors.

potent or non-active PA group included the monoester PAs, nonesterified necine bases, and PA $\mathrm{N}$-oxides.

Gao et al. [68] incubated rat hepatocytes in primary culture with various concentrations of 11 PAs over 24 and $48 \mathrm{~h}$ and determined the cytotoxicity. They found that the duration of pre-incubation had a marked influence on CYP activity, and the time-dependent decline in activity attenuated PA cytotoxicity.

Rutz et al. [64] incubated human HepG2 cells over-expressing CYP3A4 with various concentrations of 11 PAs and determined the cytotoxicity after 24 and $48 \mathrm{~h}$ and micronucleus counts after $72 \mathrm{~h}$. They found that the cytotoxic potencies of monocrotaline and europine were lower than expected from (limited) in vivo data. Lasiocarpine and most cyclic diesters were among the most potent congeners. In the micronucleus assay, monocrotaline and europine were also much less potent than expected, consistent with previous findings in HepaRG cells [65]. All PAs tested were positive in the micronucleus test in human HepG2-CYP3A4 cells. The genotoxic potencies were in somewhat better agreement with cytotoxicity data in HepG2-CYP3A4 cells than in rat primary hepatocytes.

The iREP factors for monocrotaline (1.0) and europine (0.3) overestimated the genotoxic and cytotoxic potencies of these congeners in human (and rat) cells in vitro. BMC analysis of micronuclei counts in the low concentration range revealed that 2 potent PAs, retrorsine and senecionine, exerted hypolinear concentration-response characteristics indicating a "practical threshold concentration". However, an almost linear concentration-response curve was obtained for lasiocarpine.

Thus most suggested iREP factors could be confirmed in vitro within 1 order of magnitude ( $\triangleright$ Fig. 7 ). For 2 congeners (i.e., monocrotaline and europine), more pronounced deviations were found (i.e., the in vitro potencies were substantially lower than expected from [limited] in vivo data). These differences are likely due to toxicokinetic factors not reflected sufficiently in the in vitro testing approach used so far. Concerning sensitivity towards PAs, no principal differences between rat and human cells were obvious (i.e., the rat cell types tested were not consistently more or less sensitive towards PAs than the human cell types tested). In vitro genotoxicity data indicate the possibility of a hypolinear doseresponse relationship, even for some highly potent congeners.

\section{Bioassay-Directed Analysis Approach for the Identification of Relevant PAs}

There are concerns about possible adverse health effects related to low chronic exposure of humans to PAs. These concerns are mainly related to the reported carcinogenicity of PAs in laboratory animals, which involves a genotoxic mode of action. Several hundred PAs have been identified, of which the European Commission considers 35 as relevant for monitoring food and feed [69]. From a health perspective, monitoring programs should include those 


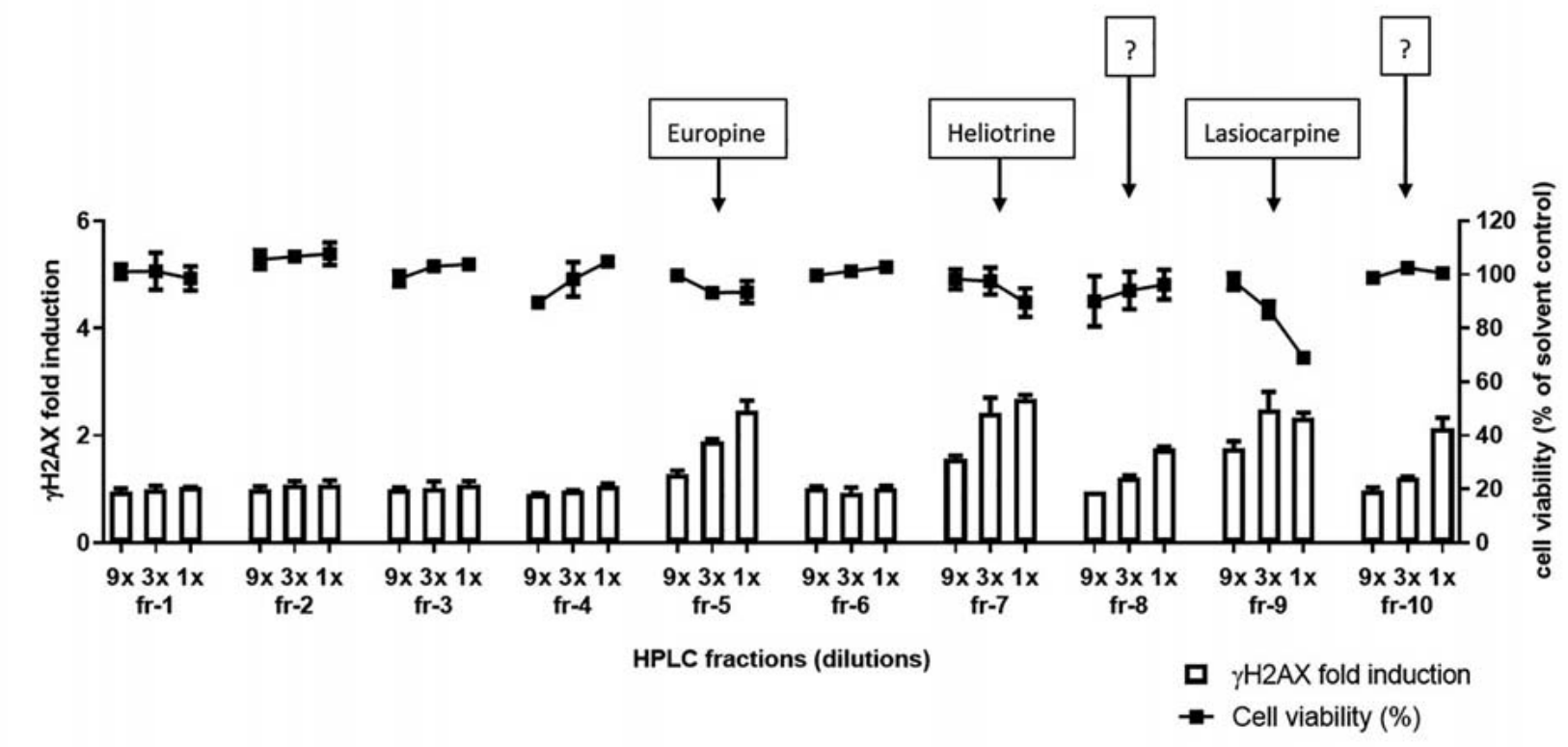

- Fig. 8 Analysis of the 10 fractions of reduced H. europaeum extract for genotoxicity ( $\gamma \mathrm{H} 2 \mathrm{AX}$ assay) and cell viability (WST-1 assay); fr stands for fraction with $x$-fold dilution as indicated.

PAs present in relevant food and feed matrices at substantial levels and that exhibit a relatively high toxic potential. Recently, the genotoxic potencies of a large number of PAs, representing diverse chemical subclasses and most of these belonging to the set of 35 PAs, have been determined in the human HepaRG liver cell line using the $\mathrm{yH} 2 \mathrm{AX}$ assay [67]. That work revealed differences in potencies spanning several orders of magnitude. In a subsequent case study, the $\mathrm{yH} 2 \mathrm{AX}$ assay was used in an effect-directed analysis approach to assess whether such an approach allows identifying so far less known but potent PAs [Peijnenburg et al., in preparation]. In this latter proof-of-principle study, an extract of Heliotropium europaeum (also known as European heliotrope or European turn-sole) was prepared and, after chemical reduction of the PA $\mathrm{N}$-oxides, analyzed for the presence of the 35 "standard" PAs using LC-MS/MS as well as for genotoxic activity using the $\gamma \mathrm{H} 2 \mathrm{AX} / \mathrm{HepaRG}$ assay. Europine, heliotrine, and lasiocarpine were found to be the most abundant PAs in the test extract. In the next step, using the methodology set-up in the EU project Euromix [70], it was shown that a ternary mixture of these 3 main PAs exhibit additive concentration effects in the $\gamma \mathrm{H} 2 \mathrm{AX}$ assay. Based on this outcome, dose-additivity was also assumed for other PAs.

Next, the $y \mathrm{H} 2 \mathrm{AX}$ activity of the extract was compared with the $\mathrm{YH} 2 \mathrm{AX}$ activity of an artificial mixture of the quantified known PAs. The $y \mathrm{H} 2 \mathrm{AX}$ signal of the plant extracts appeared to be higher than the signal of the artificial mixtures, suggesting that unknown (potent) PAs or additional constituents with genotoxic activity are present in the extracts. The extract of $H$. europaeum was fractionated using a diode array HPLC system, and the activities of the individual 10 fractions were determined in the $\gamma \mathrm{H} 2 \mathrm{AX}$ assay. The fractions were also analyzed for the 35 PAs and the necine base content using LC-MS/MS, the latter upon alkaline hydrolysis of the fractions. Five out of 10 fractions showed induction of $y \mathrm{H} 2 \mathrm{AX}$, and for 3 of the fractions, the $\mathrm{yH} 2 \mathrm{AX}$ signal was likely due to the presence of europine, heliotrine, and lasiocarpine, respectively ( $\triangleright$ Fig. 8). The activity of the 2 other fractions could not be explained based on the quantified known PAs, although necine base analysis indicated the presence of PA-like compounds in these fractions. LC-Orbitrap-MS and Compound Discoverer software (Thermo Fisher Scientific) were applied to the 2 fractions, pointing to the open diesters 5 -acetyllasiocarpine and 7-angeloylheliotrine as candidate PAs responsible for the non-explained genotoxic activity.

Thus, in summary, these results demonstrate that bioassay-directed analysis is a useful approach to identify so far lesser-known but potent PAs that would be of interest to be included in monitoring programs.

\section{Updated Relative Potency ranking of PAs and PA N-oxides Tested in the HepaRG Micronucleus Assay}

It has previously been demonstrated that the relative potencies of PAs as determined by rank ordering their genotoxicity potential differ according to their structural class $[64,65,67,71]$. PAs were generally ranked similarly across the methods/cell systems used. However, some small differences were observed (e.g., heliotrine was more potent in the micronucleus [MN] assay than in the $\gamma \mathrm{H} 2 \mathrm{AX}$ assay) $[65,67]$. Compared to their respective parent PAs, there are much fewer data reported regarding the potency of PA 


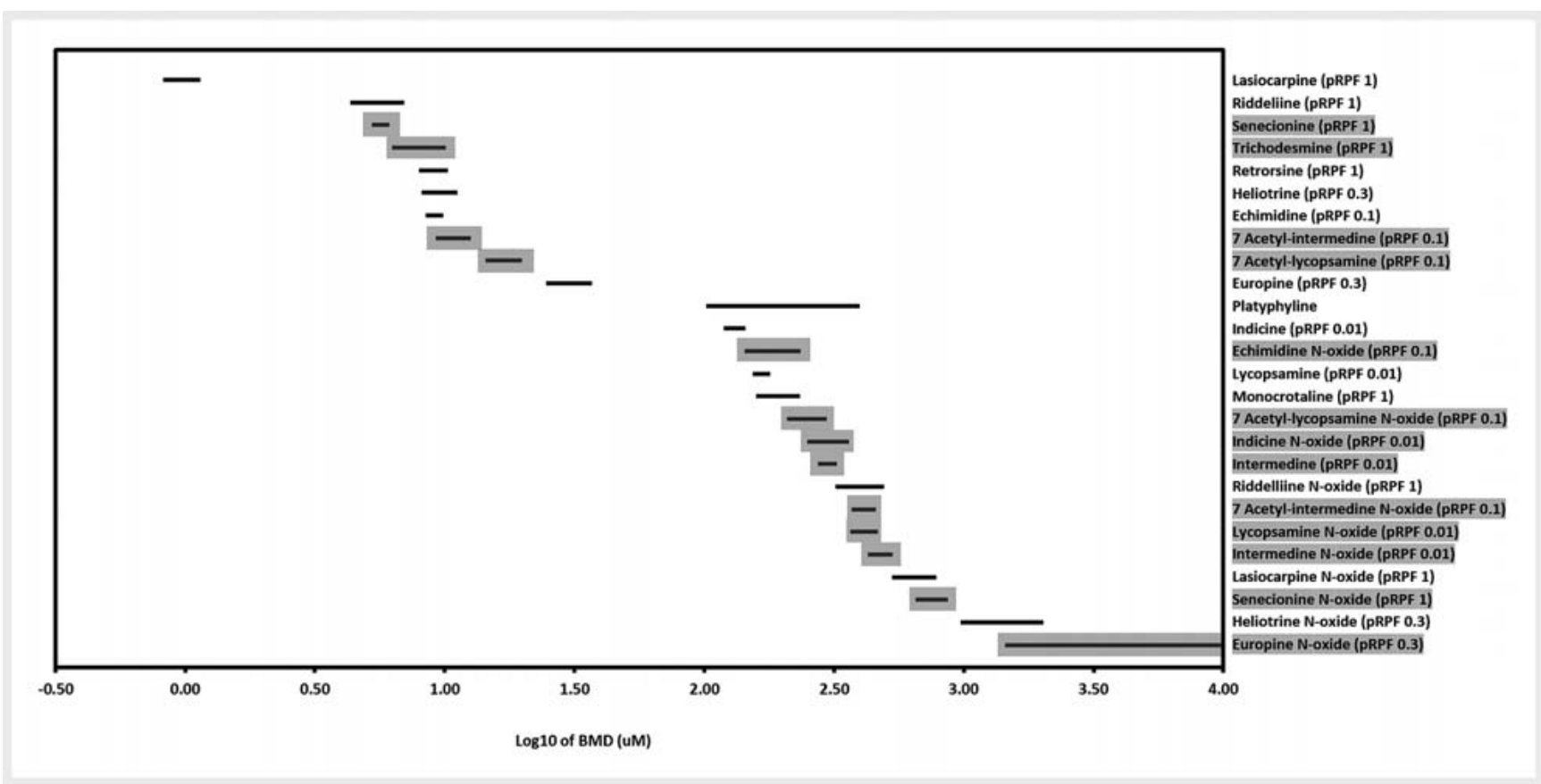

- Fig. 9 BMC confidence intervals representing a 2-fold increase in MN in HepaRG cells. Additional PAs (in grey) are presented alongside the original [65] dataset.

$\mathrm{N}$-oxides, and the data that have been reported are often negative. While it has been proposed to apply the same relative potency of the parent PA to the corresponding PA N-oxide [17], previous work demonstrated that in the MN assay, the PA $N$-oxides are substantially less potent than their respective parent PA by a factor of at least 100-fold [65], but this does not consider potential conversion back to the parent PA in vivo (e.g., by gut bacteria).

Another class of PAs with comparatively less genotoxicity data reported in the literature are the 7-acetyl derivatives. These compounds would fall within the 7R open diester PA class, with a provisional iREP factor of 0.1 . For PAs such as the $7 R$ monoesters intermedine and lycopsamine (iREP factor of 0.01), the 7-acetyl derivatives of these compounds would therefore be anticipated to be 10 -fold more potent than their respective parent PA. Indeed, this is what has been reported in both the Drosophila "wing spot test" and the HepaRG $y \mathrm{H} 2 \mathrm{AX}$ assay $[67,71]$. Similar to the PA $N$ oxides, the 7-acetyl PA $\mathrm{N}$-oxides would be assigned the same relative potency factor as their respective parent PA. Here, an expanded dataset is presented using the HepaRG MN assay to explore further the relative potency rankings of additional PA N-oxides and 7-acetyl derivatives.

For this purpose, 13 additional PAs, detailed in Supplementary Table 1S, along with the abbreviations used herein, CAS registration numbers, and the solvent used were purchased from PhytoLab GmbH \& Co. KG. (Vestenbergsgreuth, Germany) and examined. The HepaRG cells were cultured, treated, and assessed for MN using the same methods described in Allemang et al. [65]. The same data analysis was also performed for the newly generated data.
The resulting $\mathrm{BMC}$ lower and upper critical effect doses (BMCL, $\mathrm{BMCU}$ ) of the $\mathrm{MN}$ response values for the 13 additional PAs are summarized in $\boldsymbol{\sim}$ Fig. 9 , thereby extending the dataset presented in Allemang et al. [65] to a total of 27 PAs evaluated (monocrotaline $\mathrm{N}$-oxide is not shown due to the high margin of uncertainty in the BMC confidence interval). Although a slight but statistically significant increase in $\mathrm{MN}$ was observed for europine $\mathrm{N}$-oxide, the increase did not exceed 2-fold over the control. BMC analysis resulted in a very broad confidence interval (Supplementary Table $2 \mathrm{~S}$ and Supplementary Fig. 1S). Indeed, the calculated BMC for europine $N$-oxide was $2574 \mu \mathrm{M}$, well exceeding the actual concentration tested in the MN assay (Supplementary Table 1S). Senecionine and trichodesmine plotted with most other PAs of high potency, as expected given their iREP factor of 1.0. The two 7-acetyl PA derivatives showed a higher genotoxic potency than their corresponding parent compounds, as expected for PAs with a 7R open diester class (iREP factor 0.1 ) and consistent with data reported in the Drosophila "wing spot test" [71]. The higher genotoxicity of the acetylated PAs relative to their monoester counterparts may be attributed to the higher rate of metabolic conversion to the reactive pyrrolic intermediate, which may reflect their increased lipophilicity or lower base strength [72]. They also were more potent than europine, which has a higher iREP factor of 0.3 . Intermedine ranked as expected, and all additional $N$-oxides examined here were found to be less potent than the respective parent PA, consistent with observations reported in Allemang et al. in 2018 [65]. While all $\mathrm{N}$-oxides evaluated in the original 2018 dataset were separated from their parent PA by at least a factor of 100 , several PA $N$-oxides examined here were more comparable to their parent in terms of potency. Most notably, intermedine and 
intermedine $\mathrm{N}$-oxide were within a factor of 10 for reasons not known. However, the overall trend did not change in that all $11 \mathrm{~N}$-oxides were considerably less potent than the respective parent PA.

One group of PAs with little reported genotoxicity data are the 7-acetyl PA $\mathrm{N}$-oxides. It was found that 7-acetyllycopsamine $\mathrm{N}$-oxide was slightly, but distinctly (in that the confidence intervals did not overlap), more potent than the non-acetylated version. 7-acetylintermedine $\mathrm{N}$-oxide, however, was found to have a more comparable potency compared to its' non-acetylated version.

\section{Health Risks of 1,2-Unsaturated PAs in Foods- Updated Risk Assessment of the BfR}

More than 1 decade ago, 1,2-unsaturated PAs were detected in different food commodities, with honey and herbal tea being the first food groups under suspicion [5, 21, 25, 73]. Recently, the German Federal Institute for Risk Assessment (BfR) updated its assessment on health risks associated with the occurrence of 1,2unsaturated PAs in foods [30]. The primary reason for the update was new occurrence data, covering most of the relevant food groups from the German market from 2015 to mid-2019. In addition, in BfR's attempt to refine the risk assessment of 1,2-unsaturated PAs, the current literature on the toxicity of 1,2-unsaturated PAs was reviewed and carefully discussed. In particular, the growing knowledge on metabolism, genotoxicity, and (cyto)toxicity of individual congeners has recently triggered a discussion on structure-dependent differences between individual representatives from the sub-groups of PAs concerning their toxic potency. iREP factors were recently proposed to refine the estimation of the health risk [17]. However, the BfR considered the data insufficient for a congener-specific approach and based its risk assessment on approaches classifying all 1,2-unsaturated PAs as equally potent. However, a comprehensive assessment of health risks resulting from exposure to1,2-unsaturated PAs has to reflect on and consider all relevant uncertainties. Concerning the currently proposed potency factors, these are partially based on single (in vitro) endpoints and thus do not fully account for all toxicodynamic and toxicokinetic factors (e.g., the role of the gut microbiota in PA Noxide reduction, gastrointestinal uptake via transport proteins, toxification via cytochrome P450 enzymes, and detoxifying metabolism) that may influence the carcinogenic potency in real life. Thus, the BfR decided not to implement relative potency factors in its updated risk assessment yet [30].

In the assessment, only food samples were considered for which analytical data of 21 specific PAs plus the potentially coeluting natural isomers were available-this is in agreement with the recommendations in the new EU regulation (EU 2020/2040) setting maximum levels for PAs in certain foodstuffs [34]. The highest levels were in herbal tea, rooibos tea, herbs and spices, flower pollen, and rocket. However, the occurrence levels of 1,2unsaturated PAs in the current data set were lower in most food groups [30] than the levels in food samples from 2011 to 2015 considered in BfR's previous assessment [36]. This finding suggests that risk management measures have been successfully applied during recent years. In addition, these findings demonstrate the technical feasibility of reducing PA levels in food. As a direct consequence, also human exposure has declined [30]. For risk characterization, the margin of exposure (MOE) approach-which in principle describes the ratio between an appropriate toxicological reference point and the estimated human exposure-was applied, as it is commonly done in the European Union for substances that are both genotoxic and carcinogenic [74]. The formation of hepatic haemangiosarcomas has been considered the most sensitive neoplastic endpoint, and a reference point of $237 \mu \mathrm{g} / \mathrm{kg}$ body weight per day, as derived by EFSA in 2017 [1], was used for MOE calculations. The estimated chronic overall exposure calculated for all considered food groups generally resulted in MOE values above 10,000 , indicating a low concern from a public health point of view. However, it has to be noted that for high consumers, the MOE values were only slightly above 10000 . Furthermore, due to data gaps regarding consumption and/or occurrence of 1,2-unsaturated PAs, some food groups could not yet be included in the overall assessment. For example, herbs and spices could not be integrated into the overall assessment due to data gaps regarding the consumption levels. However, calculated model scenarios suggest that, even with generally low consumption, some herbs and spices may contribute considerably to human exposure [30].

Overall, the current risk assessment results revealed a positive trend towards lower PA levels in many food groups, resulting in exposure levels generally associated with MOE values above 10000 . Nevertheless, with a view on food groups with relatively high PA levels and according to the ALARA principle, the BfR still recommends further actions to reduce the overall exposure to 1,2-unsaturated PAs [30].

\section{Regulatory Perspectives of PA Contamination in Medicinal Products}

The toxicity of plants containing certain PAs has been known for a long time; severe acute cases of poisoning have been described repeatedly in humans since the beginning of the last century [75]. In addition, genotoxicity and carcinogenicity data from in vitro and in vivo (animal) studies are also available for some of the 1,2-unsaturated PAs $[56,76,77]$. Both the toxicity data, but above all the carcinogenicity data, led to the initiation of a graduated plan procedure by the German Federal Health Agency (BGA) more than 30 years ago [78], which regulated the marketability of medicinal products with PA-containing plants.

With the adoption of Directive 2004/24/EU, the Committee for Herbal Medicinal Products (HMPC) was established at the European Medicines Agency (EMA). The tasks of the HMPC include, among others, the preparation of monographs summarizing the data on efficacy and safety of herbal substances or herbal preparations after critical evaluation. They thus reflect the current state of knowledge. When questions arise (e.g., on toxicologically relevant constituents of herbal substances or preparations), the HMPC prepares supporting documents as so-called "public statements" (PS), as was necessary, for example, in the preparation of the monograph on Symphytum officinalis for the evaluation of the toxicity of PAs. 
The PS on PAs of the HMPC in the version valid at the workshop [8] defines a daily intake limit of $0.007 \mu \mathrm{g} P A / k g$ bw. Based on a body weight of $50 \mathrm{~kg}$ (derived from the Guidelines of the $\mathrm{ICH}$ and the EMA), this leads to a permitted intake of $0.35 \mu \mathrm{g} /$ day for adults. The assessment is primarily based on 2 carcinogenicity studies on lasiocarpine [79] and riddelliine [80]. In both studies, oral administration of the 2 PAs in rats resulted in haemangiosarcomas, considered the most sensitive neoplastic endpoint. The evaluation to derive the cutoff value for the risk of carcinogenicity was mainly based on the lasiocarpine study.

According to international guidelines (e.g., ICH M7) [81], both the calculation using the $\mathrm{TD}_{50}$ approach (Carcinogenic Potency Database $[\mathrm{CPDB}])$ or the definition of a benchmark dose $\left(\mathrm{BMDL}_{10}\right)$ can be chosen for defining an acceptable intake. According to both calculation methods, the limit values, which could be determined based on the lasiocarpine study, are comparable in this respect. Therefore, also for reasons of harmonization, the HMPC used in 2014 the derivation of the acceptable intakes via the $\mathrm{BMDL}_{10}$-based value of $0.007 \mu \mathrm{g} / \mathrm{kg}$ bw/day (a value derived by the EFSA [5]), although, as substantiated by the EMA [82] in principle, the $T_{50}$ approach should be used currently for medicinal products.

In July 2013, the BfR in Germany published analytical results on the occurrence of PAs in food teas (including some medicinal teas) [83]. This contamination problem was therefore already addressed in the HMPC PS [8] adopted in 2014. The Federal Institute for Drugs and Medical Devices (BfArM) published a notice on March 1, 2016, introducing a maximum limit of $1.0 \mu \mathrm{g}$ PA daily for all herbal medicinal products as a transitional measure [84]-a limit that was almost simultaneously also declared by other national competent authorities (NCAs) [85]. Accompanying these national measures, a PS on the contamination of herbal medicinal products with PAs was published by the HMPC [82]. In this, it was clarified that the transitional period mentioned by the BfArM is not expected to last longer than 3 years, after which the limit value should be set at $0.35 \mu \mathrm{g} /$ day following the recommendations of the HMPC. In January 2019, the HMPC extended the transition period for the provisional limit by another 2 years [86] to carry out a final evaluation in the context of the new publications on PAs such as by EFSA [1] and the preparation of the Ph. Eur. general method during this time.

In the final PS [87], which now combines the two PSs of the HMPC on PAs, the questions of the limit value are discussed based on the assessment modalities. However, several open questions are also addressed, such as kinetics and the derivation of potency factors for the individual PAs, which could lead to a revision of the PS and, thus, possibly of the limit value in the future.

\section{Experiences with the Code of Practice Designed for PA Management}

The discussion on potential contamination of medicinal plants with PA-containing weeds led to immediate measures in the cultivation of plants and the manufacture and quality control of the respective preparations and medicinal products. To minimize their PA content, a Code of Practice [9] was established that pro- vides a framework for the implementation of individual measures along the entire process chain covering, for example, selection of seeds, cultivation, harvesting, incoming goods inspection, and processing steps up to the release of the final medicinal product. Its main principle is to identify potential risks for each process step and their probability of occurrence and proposed measures to be undertaken, followed by an assessment of these measures concerning feasibility, time horizon, and efficiency.

Evaluation of the annual manufacturers' data collection from analytical testing between 2013 and 2020 showed an overall reduction of PA levels. It confirmed the efficacy of the measures recommended by the Code of Practice. For the most important herbal drugs and extracts, the following developments concerning the regulatory limits for the final product of 0.35 or $1.0 \mu \mathrm{g} \mathrm{PA}$ per day set by others $[8,82]$ can be seen nowadays:

- The proportion of samples with a PA content of more than $1.0 \mu \mathrm{g} /$ day for herbal drugs is relatively stable with $41 \%$ in 2020. For herbal extracts, this proportion is much lower than for herbal drugs and also stable with 14\% in 2020.

- For herbal drugs, the proportion of samples keeping the limits of $0.35 \mu \mathrm{g} /$ day and $1.0 \mu \mathrm{g} /$ day, respectively, is also stable now. The proportion of samples keeping the limit of $1.0 \mu \mathrm{g} /$ day was at $59 \%$ (i.e., considerably higher than the $41 \%$ of samples keeping the limit of $0.35 \mu \mathrm{g} /$ day). For herbal extracts, the respective proportions of samples are also considered stable now.

However, the results also show that despite all measures to minimize the PA content, a general limit of $0.35 \mu \mathrm{g}$ PA per day as set in 2014 [8] is not considered appropriate by the manufacturers since it cannot be kept by more than $50 \%$ of the most important herbal drugs.

The HMPC Public Statement of November 24, 2014 [8], which recommended a maximum daily intake of $0.35 \mu \mathrm{g}$ PA per day, was updated in July 2020 and published after final adoption [87]. It refers to the EFSA risk assessment [1] and states that a daily intake of $1.0 \mu \mathrm{g}$ PA per day for adults applies, also for contaminations of medicinal products. Thus, it confirms the limit set by the HMPC in May 2016 [82] as a transitional limit for 3 years and later extended to 5 years. It was finalized in July 2021 [87].

For the determination of PA today, LC-MS/MS technologies are used. The new Ph.Eur. general chapter 2.8.26. Contaminant PAs [35] describes an analytical procedure suitable for the determination of 28 target PAs. The chapter permits the use of any procedure consisting of chromatography coupled with MS/MS or highresolution MS if specific validation requirements are met.

The application of the Code of Practice, particularly the measures of manufacturers to reduce the contamination in collaboration with herb growers, has revealed positive results confirmed by the industry's database evaluation over the past years. Nonetheless, contamination of plant material with PA still poses a big challenge for growers and manufacturers.

\section{Summary and Conclusions}

Except for a few edible plants, PAs are in most cases introduced in the food chain due to contamination with PA-containing weeds. 
Thanks to highly selective and sensitive techniques and the enhanced availability of analytical standards, the possibility of monitoring food products for PAs has greatly improved. Besides the PA-producing plant borage, PA levels exceeding $10 \mathrm{mg} / \mathrm{kg}$ have been found in culinary herbs, particularly oregano. In herbal teas and supplements, the typical contamination level is somewhat lower, with concentrations occasionally exceeding $1 \mathrm{mg} / \mathrm{kg}$ and retail honey typically falling well below $100 \mu \mathrm{g} / \mathrm{kg}$. In recent years, there has been a downward trend in the observed PA levels for honey, herbal teas, and herbal food supplements, but not for pollen supplements and culinary herbs and spices. A new EU legislation specifying maximum total PA levels in herbal and flavored teas, herbal food supplements, pollen-based supplements, borage, and culinary herbs and spices will help to reduce PA-contamination of food further. For herbal medicinal products, European legislation foresees a maximum daily intake of $1.0 \mu \mathrm{g}$ PAs per day from such products.

Differences in ADME characteristics of PAs may substantially influence PA toxicity, and these can be taken into account for the risk assessment by PBK modeling. It allows converting in vitro concentration-response data on PA toxicity to the in vivo situation, taking differences in ADME characteristics into account.

Analysis of all naturally occurring PAs with a 1,2-unsaturated necine base structure showed that only a few marker alkaloids account for most of the total PA content in many plants. Thus, the proposed analytical scope for determining maximum levels comprises 21 PAs +14 of their isomers. Studies on microsomal metabolism of PAs revealed higher transformation rates in rat liver microsomes compared to humans. Metabolites can be classified into reactive pyrrolic metabolites, including their conjugation products with GSH and other metabolites ( $N$-oxides, hydroxylation, epoxidation, or dealkylation products). The pattern of metabolites can provide a better insight into the mode of action and toxic potency of individual PA congeners.

The ratio of DNA adducts to AUC (adducts/AUC) of the PA provides a measure of the intrinsic hepatic potency of each $P A$, reflecting hepatocyte exposure to DNA reactive metabolites. DNA adduct formation was observed to be linear with AUCs at PA concentrations ranging from 10 to $100 \mu \mathrm{M}$. Extrapolation to lower physiologically relevant concentrations (AUCs, respectively) combined with intrinsic potency values allows an overall potency ranking. Using this approach and taking into account toxicokinetics, potency differences spanning 3-orders of magnitude were observed with a preliminary PBK modeling approach. A similar rank order of potencies was observed with $\mathrm{N}$-oxides, which were predicted to be 2-10-fold-less potent than their respective free base. Permeability studies in $\mathrm{Caco}-2$ cells show that $\mathrm{N}$-oxides and monoesters exhibit low permeability, whereas representative diesters have moderate gut permeability. Such properties may contribute to the observed differences between some iREPs and in vitro relative potency factors. However, $\mathrm{N}$-oxides can be converted to the free base by gut microbiota and subsequently metabolized mainly in the liver, an important consideration in determining their relative potency.

The genotoxic mechanism of PAs is mediated by a set of DHP-DNA adducts (i.e., DHP-dG-3, DHP-dG-4, DHP-dA-3, and DHP-dA-4). DNA-reactive pyrrolic metabolites are unique in that they are all bifunctional alkylating agents capable of binding to nucleophilic sites (-SH, - $\mathrm{NH}$, and $\mathrm{OH}$ groups). In addition to primary pyrrolic metabolites, 10 secondary pyrrolic metabolites, including 7-glutathione-DHP (7-GS-DHP), 7-cysteine-DHP, and 7-Nacetylcystyeine-DHP (7-NAC-DHP), have been identified. They are also DNA-reactive and capable of binding to cellular DNA to produce DHP-dG-3, DHP-dG-4, DHP-dA-3, and DHP-dA-4. Some secondary pyrrolic metabolites are commonly formed from the metabolism of PAs and PA $\mathrm{N}$-oxides in vitro and may play an important role in PA-induced tumorigenicity.

Under circumstances of deficient DNA repair, linear dose-responses of DNA adduct and colorectal cancer formation are found (e.g., in mice treated with genotoxic NOC). In contrast, nonlinear dose-responses are found in wild-type mice. The levels of the DNA damage marker $\gamma$-H2AX correlated very well with the observed dose-responses in cancer formation. Concentration-dependent micronuclei induction in CYP3A4-expressing HepG2 cells also showed hypo-linearity with senecionine and retrorsine but not with lasiocarpine. The BMC for a $100 \%$ increase of micronuclei over control were found to be $0.04 \mu \mathrm{M}$ for lasiocarpine, $0.1 \mu \mathrm{M}$ for senecionine, and $1.3 \mu \mathrm{M}$ for retrorsine. Preliminary studies indicate a linear concentration-response curve in lasiocarpine-triggered $\gamma \mathrm{H} 2 \mathrm{AX}$ formation. It is tempting to speculate that repair mechanisms may influence the shape of the concentration-response curve in PA-induced genotoxicity.

The assignment of iREP factors to PAs is currently based on their combined genotoxic potency in Drosophila, cytotoxic potency in vitro, and acute toxicity in adult rodents. There is a need to refine further iREP factors based on in vitro studies, focusing on liver toxicity and carcinogenicity. In rat hepatocytes in primary culture and human HepG2 cells over-expressing CYP3A4, the cytotoxic and genotoxic (HepG2 only) potencies of monocrotaline and europine were lower than expected from iREP factors. In contrast, the factors for monocrotaline (1.0) and europine (0.3) overestimated the potencies. A benchmark concentration analysis of micronuclei counts in the low concentration range revealed that retrorsine and senecionine but not lasiocarpine exerted hypolinear concentration-response characteristics indicating a practical threshold concentration for genotoxicity.

A large number of PAs has been analyzed in HepaRG cells using the $y \mathrm{H} 2 \mathrm{AX}$ assay. That work revealed differences in potencies spanning several orders of magnitude. In addition, the $\gamma \mathrm{H} 2 \mathrm{AX}$ assay was used to assess the presence of potent PAs in a mixture. An extract of $H$. europaeum, with europine, heliotrine, and lasiocarpine as the major PAs, was also analyzed for genotoxicity. A ternary mixture consisting of equipotent concentrations of these 3 main PAs exhibited additive concentration effects in the $y \mathrm{H} 2 \mathrm{AX}$ assay. The $\mathrm{y} 2 \mathrm{AX}$ signal of the plant extracts appeared to be higher than the signal of an artificial preparation of the quantified known PAs, suggesting that unknown (potent) PAs were present in the extract. The latter was fractionated, and the genotoxic activities of the individual 10 fractions were determined in the $\gamma \mathrm{H} 2 \mathrm{AX}$ assay. In some fractions, the activity could not be explained based on the levels of PAs. These results demonstrate that bioassay-directed analysis can be a useful approach to identify lesser-known but potent PAs and other genotoxic constituents. 
When additional PA $\mathrm{N}$-oxides and 7-acetyl derivatives were analyzed in the HepaRG micronucleus assay, europine $\mathrm{N}$-oxide exhibited a very low potency while senecionine and trichodesmine were among the highly potent congeners attributed with an iREP factor of 1. Two 7-acetyl PA derivatives tested showed a higher genotoxic potency than their corresponding parent compounds, as expected for PAs with a 7R open diester class (iREP factor 0.1) and consistent with data reported in the Drosophila "wing spot test". Most $\mathrm{N}$-oxides examined were less potent by a factor of at least 100 than the respective parent PA. Several PA $N$-oxides, most notably intermedine $\mathrm{N}$-oxide, were more comparable (i.e., within a factor of 10 to their parent in terms of potency). Among the 7-acetyl PA $\mathrm{N}$-oxides, 7-acetyllycopsamine $\mathrm{N}$-oxide was slightly more potent than the non-acetylated counterpart, while 7-acetylintermedine $\mathrm{N}$-oxide had a genotoxic potency similar to its' nonacetylated version.

Recently, the BfR updated its assessment on health risks associated with the occurrence of 1,2-unsaturated PAs in foods based on new exposure data. In its risk assessment, all 1,2-unsaturated PAs were classified as equally potent since the available data regarding relative potency factors were not considered sufficient by the BfR for a congener-specific approach from a regulatory perspective. In the assessment, the highest levels were observed in herbal tea, rooibos tea, herbs and spices, flower pollen, and rocket. However, the occurrence levels of 1,2-unsaturated PAs were lower in most food groups than from 2011 to 2015. The estimated chronic overall exposure resulted in MOE values above 10,000 , indicating a low concern, although, for high consumers, the MOE values were only slightly above 10,000 . Furthermore, due to data gaps regarding consumption and/or occurrence of PAs in some herbs and spices, these could not yet be included in the overall assessment. However, model scenarios suggest that these may contribute considerably to human exposure. Thus, it is still recommended to further take actions to reduce the overall exposure to 1,2-unsaturated PAs.

Concerns about the toxicity and carcinogenicity of certain PAs led to the initiation of a graduated plan procedure by the former BGA and medicinal products with PA-containing plants more than 30 years ago. In 2014, the HMPC published a public statement on PAs at the EMA. It defined a daily intake limit of $0.007 \mu \mathrm{gA} / \mathrm{kg}$ bw based on a rat carcinogenicity study with lasiocarpine. Then, several National Competent Authorities in Europe introduced a maximum limit of $1.0 \mu \mathrm{g}$ PA daily for all herbal medicinal products as a transitional measure in 2016. In 2019, the HMPC extended the transition period by another 2 years. In an updated draft PS (published on July 8, 2020), the limit value is discussed based on the assessment modalities and set at $1.0 \mu \mathrm{g} /$ day for adults. Furthermore, the question of kinetics and the derivation of potency factors for the individual PAs, which could lead to a revision of the public statement and thus possibly of the limit value in the future, are discussed.

The potential contamination of medicinal plants with PA-containing weeds led to immediate measures in the cultivation of plants and manufacture and quality control. A consortium of manufacturers established a Code of Practice, which provides a framework for implementing individual measures along the entire production process. Its main principle is identifying potential risks for each process step together with their probability of occurrence and proposed measures to be undertaken. Evaluation of data from analytical testing between 2013 and 2020 showed an overall reduction of PA levels and confirmed the efficacy of the Code of Practice. The results of the database evaluation indicate that despite all measures to minimize the PA content, a general limit of $0.35 \mu \mathrm{g}$ PA per day is not considered appropriate by the manufacturers since it cannot be kept by more than $50 \%$ of the most important herbal drugs.

In conclusion, the workshop revealed a clearer picture of levels and exposure to PAs related to the consumption/intake of food, feed, and phytomedicines. Further development of analytical methods and a common approach to the list of PAs to be determined on a routine basis has been brought forward. At the same time, the picture of human exposure via herbal teas, honey, and phytomedicines has become much clearer. However, sources of PA exposure via spices, condiments, and food supplements warrant further investigation. There is also a clear need for more consideration of the in vitro data relevant to the in vivo situation to generate a broader basis for the risk assessment of PAs. This is last but not least due to the ever-increasing restrictions for animal experiments combined with a large number of PAs of relevance. It became obvious that not only refinement of the current methods on toxic effects and the underlying modes of action but also the modeling of toxicokinetics based on in vitro data is mandatory.

Furthermore, the findings demonstrate that the assumption that all 1,2-unsaturated PAs assayed by routine control were equally potent and as toxic as the most potent congeners is scientifically incorrect. However, more work is needed to provide a basis for a broader acceptance of relative potency factors in PA risk assessment, taking individual PAs' kinetic properties into account. It became obvious that the assumption that $\mathrm{N}$-oxides, the predominant form in many plants, being as potent as the parent PAs is a conservative approach and may over-estimate the risk. Finally, attempts were discussed to limit the exposure of consumers and patients via mitigation measures and the setting of maximum values. This process is ongoing and needs more scientific input to ensure that PA contaminations in food, feed, and phytomedicines can be limited to a safe level causing no harm to consumers and patients.

\section{Disclaimer}

This article is not an official U.S. Food and Drug Administration (FDA) guidance or policy statement. No official support or endorsement by the U.S. FDA is intended or should be inferred.

\section{Contributors' Statement}

Conception and design, analysis and interpretation, drafting of the manuscript, critical revision of the manuscript: D. Schrenk. Data collection, analysis and interpretation of the data, drafting the manuscript, critical revision of the manuscript: A. Allemang, J. Fahrer, P. P. Fu, G. Lin, C. Mahony, P. P.J. Mulder, A. Peijnenburg, S. Pfuhler, M. C. M. Rietjens, B. Sachse, B. Steinhoff, A. These, J. Troutman, J. Wiesner. 


\section{Acknowledgements}

The authors want to acknowledge the work of their colleagues and collaborators who have contributed substantially to the original work (which has been published or is in the publication process of the special issue or elsewhere) discussed in this review: Marc Audebert, Greg Dameron, Mona Delagrange, Andrea Edginton, Lan Gao, Ina Geburek, Arjen Gerssen, Wendy Jansen Holleboom, Mike Karb, James Keating, Jan-Heiner Küpper, Cathy Lester, Jochem Louisse, Jiang Ma, Karl-Heinz Merz, Cindy Obringer, Deborah Rijkers, Lukas Rutz, Milou van de Schans, Bernd Schäfer, and Geert Stoopen.

\section{Conflict of Interest}

The authors declare that they have no conflict of interest.

\section{References}

[1] EFSA (European Food Safety Authority). Scientific Panel on Contaminants in the Food Chain (CONTAM). Risks for human health related to the presence of pyrrolizidine alkaloids in honey, tea, herbal infusions and food supplements. EFSA J 2017; 15: 4908

[2] Bodi D, Ronczka S, Gottschalk C, Behr N, Skibba A, Wagner M, LahrssenWiederholt M, Preiss-Weigert A, These A. Determination of pyrrolizidine alkaloids in tea, herbal drugs and honey. Food Add Contam 2014; A31: 1886-1895

[3] Schulz M, Meins ], Diemert S, Zagermann-Muncke P, Goebel R, Schrenk D, Schubert-Zsilavecz M, Abdel-Tawab M. Detection of pyrrolizidine alkaloids in German licensed herbal medicinal teas. Phytomedicine 2015; 22: 648-656

[4] COT (Committee on Toxicity of Chemicals in Food, Consumer, Products and the Environment). Statement on Pyrrolizidine Alkaloids in Food (October 2008). Accessed October 12, 2021 at: http://cot.food.gov.uk/ pdfs/cotstatementpa200806.pdf

[5] EFSA (European Food Safety Authority). Scientific opinion on pyrrolizidine alkaloids in food and feed. Panel on Contaminants in the Food Chain (CONTAM). EFSA J 2011; 9: 2406

[6] EFSA (European Food Safety Authority). Dietary exposure assessment to pyrrolizidine alkaloids in the European population. EFSA J 2016; 14 4572, doi:10.2903/j.efsa.2016.4572

[7] EMA (European Medicines Agency). Public statement on the use of herbal medicinal products containing toxic, unsaturated pyrrolizidine alkaloids (July 8, 2020). EMA/HMPC/893108/2011. Accessed October 12 , 2021 at: https://www.ema.europa.eu/en/documents/public-statement/ draft-public-statement-use-herbal-medicinal-products-containingtoxic-unsaturated-pyrrolizidine_en-0.pdf

[8] EMA (European Medicines Agency). Public statement on the use of herbal medicinal products containing toxic, unsaturated pyrrolizidine alkaloids (PAs) (November 24, 2014). EMA/HMPC/893108/2014, final version. Accessed October 12, 2021 at: europa.eu/en/documents/ public-statement/public-statement-use-herbal-medicinal-productscontaining-toxic-unsaturated-pyrrolizidine-alkaloids_en.pdf

[9] BAH/BPI. Letter to the editor: Code of practice to prevent and reduce pyrrolizidine alkaloid contaminations of medicinal products of plant origin (April 29, 2016). J Appl Res Med Arom Plants (September 19, 2016). Accessed October 12, 2021 at: http://www.journals.elsevier.com/ journal-of-applied-research-on-medicinal-and-aromatic-plants/news

[10] Tandon BN, Tandon RK, Tandon HD, Narndranathan M, Joshi YK. Epidemic of veno-occlusive disease of liver in Central India. Lancet 1976; 2, 271-272

[11] Mohabbat O, Srivastava RN, Younos MS, Merzad AA, Sediq GG, Aram $\mathrm{GN}$. Outbreak of hepatic veno-occlusive disease in northwestern Afghanistan. Lancet 1976; 2: 269-271
[12] Clayton M], Davis TZ, Knoppel EL, Stegelmeier BL. Hepatotoxic plants that poison livestock. Vet Clin North Am Food Anim Pract 2020; 36: 715-723

[13] Stewart M], Steenkamp V. Pyrrolizidine poisoning: a neglected area in human toxicology. Ther Drug Monit 2001; 23: 698-708

[14] Xiao R, Zhu L, Su Y, Zhang J, Lu Y, Li ], Wang T, Fang J, Jing ZC, Dupuis ], Luo $\mathrm{S}$, Hu Q. Monocrotaline pyrrole induces pulmonary endothelial damage through binding to and release from erythrocytes in lung during venous blood reoxygenation. Am J Physiol Lung Cell Mol Physiol 2019; 316 : L798-L809

[15] He X, Xia Q, Woodling K, Lin G, Fu PP. Pyrrolizidine alkaloid-derived DNA adducts are common toxicological biomarkers of pyrrolizidine alkaloid N-oxides. J Food Drug Anal 2017; 25: 984-991

[16] FAO/WHO. Joint FAO/WHO Expert Committee on Food Additives (JECFA)-Eightieth meeting. Rome, 16-25 June 2015 (July 6, 2015). Accessed October 12, 2021 at: http://www.fao.org/fileadmin/user_upload/agns/ pdf/jecfa/Summary_report_of_the_80th_JECFA_meeting.pdf

[17] Merz KH, Schrenk D. Interim relative potency factors for the toxicological risk assessment of pyrrolizidine alkaloids in food and herbal medicines. Toxicol Lett 2016; 263: 44-57

[18] JECFA (Joint FAO/WHO Expert Committee on Food Additives). Safety evaluation of certain food additives and contaminants: Prepared by the eightieth meeting of the Joint FAO/WHO Expert Committee on Food Additives (JECFA). Supplement 2: Pyrrolizidine alkaloids. WHO Food Additives Series, No. 71-S2. Geneva; World Health Organization; 2020

[19] Yang M, Ma J, Ruan J, Ye Y, Fu PPC, Lin G. Intestinal and hepatic biotransformation of pyrrolizidine alkaloid $\mathrm{N}$-oxides to toxic pyrrolizidine alkaloids. Arch Toxicol 2019; 93: 2197-2209

[20] Edgar JA, Roeder E, Molyneux RJ. Honey from plants containing pyrrolizidine alkaloids: A potential threat to health. J Agric Food Chem 2002; 50 : 2719-2730

[21] BfR (Bundesinstitut für Risikobewertung). Analytik und Toxizität von Pyrrolizidinalkaloiden sowie eine Einschätzung des gesundheitlichen Risikos durch deren Vorkommen in Honig. Stellungnahme Nr. 038/2011 des BfR, 2011 (August 11, 2011). Accessed October 12, 2021 at: https://www.bfr.bund.de/de/a-z_index/pyrrolizidinalkaloide-127028. html

[22] Dübecke A, Beckh G, Lüllmann C. Pyrrolizidine alkaloids in honey and bee pollen. Food Add Contam 2011; A28: 348-358

[23] BfR (Bundesinstitut für Risikobewertung). Aktualisierte Risikobewertung zu Gehalten an 1, 2-ungesättigten Pyrrolizidinalkaloiden (PA) in Lebensmitteln. Stellungnahme 026/2020 (June 17, 2020). Accessed October 12, 2021 at: https://www.bfr.bund.de/de/a-z_index/ pyrrolizidinalkaloide-127028.html

[24] BfR (Bundesinstitut für Risikobewertung). Pyrrolizidinalkaloidgehalt in getrockneten und tiefgefrorenen Gewürzen und Kräutern zu hoch. Stellungnahme Nr. 017/2019 (June 17, 2019). Accessed October 12, 2021 at: https://www.bfr.bund.de/de/a-z_index/pyrrolizidinalkaloide127028.html

[25] Kaltner F, Rychlik M, Gareis M, Gottschalk C. Occurrence and risk assessment of pyrrolizidine alkaloids in spices and culinary herbs from various geographical origins. Toxins 2020; 12: 155

[26] BfR (Bundesinstitut für Risikobewertung). Pyrrolizidine alkaloids in herbal teas and teas. Opinion No. 018/2013 (July 5, 2013). Accessed October 12, 2021 at: https://www.bfr.bund.de/cm/349/pyrrolizidinealkaloids-in-herbal-teas-and-teas.pdf

[27] Mulder PPJ, López Sánchez P, These A, Preiss-Weigert A, Castellari M. Occurrence of pyrrolizidine alkaloids in food. EFSA supporting publication [Epub 2015 July 23] EN-859, 116 pp. Accessed October 12, 2021 at: http://www.efsa.europa.eu/en/supporting/pub/en-859

[28] Mulder PP], López P, Castellari M, Bodi D, Ronczka S, Preiss-Weigert A These A. Occurrence of pyrrolizidine alkaloids in animal-and plant-derived food: Results of a survey across Europe. Food Add Contam A 2018; 35: 118-133 
[29] Picron JF, Herman M, Van Hoeck E, Goscinny S. Analytical strategies for the determination of pyrrolizidine alkaloids in plant based food and examination of the transfer rate during the infusion process. Food Chem 2018; 266: 514-523

[30] Kaltner F, Kukula V, Gottschalk C. Screening of food supplements for toxic pyrrolizidine alkaloids. J Consum Prot Food Safety 2020; 15: 237243

[31] Kast C, Kilchenmann V, Reinhard H, Droz B, Lucchetti MA, Dübecke A, Beckh G, Zoller O. Chemical fingerprinting identifies Echium vulgare, Eupatorium cannabinum and Senecio spp. as plant species mainly responsible for pyrrolizidine alkaloids in bee-collected pollen. Food Addit Contam A 2017; 35: 316-327

[32] Picron JF, Herman M, Van Hoeck E, Goscinny S. Monitoring of pyrrolizidine alkaloids in beehive products and derivatives on the Belgian market. Environ Sci Pollut Res Int 2020; 27: 5693-5708

[33] BfR (Bundesinstitut für Risikobewertung). Pyrrolizidinalkaloide: Gehalte in Lebensmitteln sollen nach wie vor soweit wie möglich gesenkt werden. Stellungnahme Nr. 030/2016 des BfR vom 28. September 2016. Accessed October 12, 2021 at: https://www.bfr.bund.de/de/a-z_index/ pyrrolizidinalkaloide-127028.html

[34] EC (European Commission). Commission Regulation (EU) 2020/2040 of December 11, 2020, amending Regulation (EC) No 1881/2006 as regards maximum levels of pyrrolizidine alkaloids in certain foodstuffs. Off J EU 2020; L420: 1-5

[35] European Pharmacopoeia. New Ph. Eur. Chapter Contaminant pyrrolizidine alkaloids (2.8.26). Supplement 10.6 of July 1, 2021. Accessed October 12, 2021 at: https://www.ema.europa.eu/en/documents/minutes/ minutes-hmpc-5-7-july-2021-meeting_en.pdf

[36] Chen L, Ning J, Louisse J, Wesseling S, Rietjens IMCM. Use of physiologically based kinetic modelling facilitated reverse dosimetry to convert in vitro cytotoxicity data to predicted in vivo liver toxicity of lasiocarpine and riddelliine in rat. Food Chem Toxicol 2018; 116: 216-226

[37] Ning J, Chen L, Rietjens IMCM. Role of toxicokinetics and alternative testing strategies in pyrrolizidine alkaloid toxicity and risk assessment; stateof-the-art and future perspectives. Food Chem Toxicol 2019; 131: 110572

[38] Lester C, Troutman J, Obringer C, Wehmeyer K, Stofolano P, Karb M, Xu Y, Roe A, Carr G, Blackburn K, Mahony C. Intrinsic relative potency of a series of pyrrolizidine alkaloids characterized by rate and extent of metabolism. Food Chem Toxicol 2019; 131: 110523

[39] Yang M, Ma J, Ruan J, Zhang C, Ye Y, Fu PPC, Lin G. Absorption difference between hepatotoxic pyrrolizidine alkaloids and their $\mathrm{N}$-oxides-Mechanism and its potential toxic impact. J Ethnopharmacol 2020; 249: 112421

[40] Tu M, Sun S, Wang K, Peng X, Wang R, Li L, Zeng S, Zhou H, Jiang H. Organic cation transporter 1 mediates the uptake of monocrotaline and plays an important role in its hepatotoxicity. Toxicology 2013; 311: 225230

[41] Tu M, Li L, Lei H, Ma Z, Chen Z, Sun S, Zu S, Zhou H, jiang H. Involvement of organic cation transporter 1 and CYP3A4 in retrorsine-induced toxicity. Toxicology 2014; 322: 34-42

[42] Louisse J, Beekmann K, Rietjens IMCM. Use of physiologically based kinetic modeling-based reverse dosimetry to predict in vivo toxicity from in vitro data. Chem Res Toxicol 2017; 30: 114-125

[43] Suparmi S, Wesseling S, Rietjens IMCM. Monocrotaline-induced liver toxicity in rat predicted by a combined in vitro-physiologically based kinetic modeling approach. Arch Toxicol 2020; 138: 111230

[44] Stegelmeier BL, Edgar JA, Colegate SM, Gardner DR, Schoch TK, Coulombe RA, Molyneux RJ. Pyrrolizidine alkaloid plants, metabolism and toxicity. J Nat Toxins 1999; 8: 95-116

[45] Wang Q, Spenkelink B, Boonpawa R, Rietjens IMCM, Beekmann K. Use of physiologically based kinetic modelling to predict rat gut microbial metabolism on the isoflavone daidzein to $\mathrm{S}$-equol and its consequences for ERa activation. Mol Nutr Food Res 2020; 64: 1900912
[46] Maedge I, Gehling M, Schoene C, Winterhalter P, These A. Pyrrolizidine alkaloid profiling of four Boraginaceae species from Northern Germany and implications for the analytical scope proposed for monitoring of maximum levels. Food Add Contam Part A 2020; 388: 1339-1358

[47] BVL (Bundesamt für Verbraucherschutz und Lebensmittelsicherheit). BVL-Report - 11.3, Berichte zur Lebensmittelsicherheit: Monitoring 2015. Accessed October 12, 2021 at: https://www.bvl.bund.de/SharedDocs/Downloads/01_Lebensmittel/01_Im_mon_dokumente/01_ Monitoring_Berichte/2015_Im_monitoring_bericht.pdf?_blob= publicationFile\& $=6$

[48] Geburek I, Preiss-Weigert A, Lahrssen-Wiederholt M, Schrenk D, These A. In vitro metabolism of pyrrolizidine alkaloids-metabolic degradation an GSH conjugate formation of different structure types. Food Chem Toxicol 2020; 135: 110868. doi:10.1016/j.fct.2019.110868

[49] Geburek I, Schrenk D, These A. In vitro biotransformation of pyrrolizidine alkaloids in different species. Part II: Identification and quantitative assessment of the metabolite profile of six structurally different pyrrolizidine alkaloids. Arch Toxicol 2020; 94: 3759-3774

[50] Fu PP, Chou MW, Churchwell M, Wang Y, Zhao Y, Xia Q, Gamboa da Costa G, Matilde M, Beland FA, Doerge DR. Detection and quantitation of pyrrolizidine alkaloid-derived DNA adducts in vivo and in vitro by liquid chromatography-electrospray ionization-tandem mass spectrometry. Chem Res Toxicol 2010; 23: 637-652

[51] Xia Q, Zhao Y, Von Tungeln LS, Doerge D, Lin G, Cai L, Fu PP. Pyrrolizidine alkaloids derived DHP-DNA adducts are a common biological biomarker of pyrrolizidine alkaloid-initiated tumorigenicity. Chem Res Toxicol 2013; 26: 1384-1396

[52] Fu PP. Pyrrolizidine alkaloids: metabolic activation pathways leading to liver tumor initiation. Chem Res Toxicol 2017; 30: 81-93

[53] Xia Q, He X, Ma L, Chen S, Fu PP. Pyrrolizidine alkaloid secondary pyrrolic metabolites construct multiple activation pathways leading to DNA adduct formation and potential liver tumor initiation. Chem Res Toxicol 2018; 31: 619-628

[54] He X, Xia Q, Gamboa da Costa G, Lin G, Fu PP. 1-Formyl-7-hydroxy-6,7dihydro-5H-pyrrolizine (1-CHO-DHP)-a potential proximate carcinogenic metabolite of pyrrolizidine alkaloids. Chem Res Toxicol 2019; 32: 1193-1203

[55] He X, Xia Q, Zhao Y, Fu PP. 1-Formyl-7-hydroxy-6,7-dihydro-5H-pyrrolizine (1-CHO-DHP)-cysteine conjugates: metabolic formation and binding to cellular DNA. Chem Res Toxicol 2020; 33: 2139-2146

[56] Chen L, Peijnenburg A, de Haan L, Rietjens IMCM. Prediction of in vivo genotoxicity of lasiocarpine and riddelliine using a combined in vitrophysiologically based kinetic modelling-facilitated reverse dosimetry approach. Arch Toxicol 2019; 93: 2385-2395

[57] Fu PP. · Pyrrolizidine alkaloids: Metabolic activation pathways leading to liver tumor initiation. Chem Res Toxicol 2017; 30: 81-93

[58] Fahrer ], Kaina B. $\mathrm{O}^{6}$-methylguanine-DNA methyltransferase in the defense against $\mathrm{N}$-nitroso compounds and colorectal cancer. Carcinogenesis 2013; 34: 2435-2442

[59] Fahrer ], Kaina B. Impact of DNA repair on the dose-response of colorectal cancer formation induced by dietary carcinogens. Food Chem Toxicol 2017; 106: 583-594

[60] Kaina B, Christmann M, Naumann S, Roos WP. MGMT: key node in the battle against genotoxicity, carcinogenicity and apoptosis induced by alkylating agents. DNA Repair (Amst) 2007; 6: 1079-1099

[61] Fahrer J, Frisch J, Nagel G, Kraus A, Dörsam B, Thomas AD, Reißig S, Waisman A, Kaina B. DNA repair by MGMT, but not AAG, causes a threshold in alkylation-induced colorectal carcinogenesis. Carcinogenesis 2015; 36: 1235-1244

[62] Kraus A, McKeague M, Seiwert N, Nagel G, Geisen SM, Ziegler N, Trantakis IA, Kaina B, Thomas AD, Sturla S], Fahrer J. Immunological and mass spectrometry-based approaches to determine thresholds of the mutagenic DNA adduct O(6)-methylguanine in vivo. Arch Toxicol 2019; 93: 559-572 
[63] Lutz WK, Lutz RW. Statistical model to estimate a threshold dose and its confidence limits for the analysis of sublinear dose-response relationships, exemplified for mutagenicity data. Mutat Res 2009; 678: 118-122

[64] Rutz L, Gao L, Küpper JH, Schrenk D. Structure-dependent genotoxic potencies of selected pyrrolizidine alkaloids in metabolically competent HepG2 cells. Arch Toxicol 2020; 94: 4159-4172

[65] Allemang A, Mahony C, Lester C, Pfuhler S. Relative potency of fifteen pyrrolizidine alkaloids to induce DNA damage as measured by micronucleus induction in HepaRG human liver cells. Food Chem Toxicol 2018; 121: 72-81

[66] Rogiers V. Recent developments in the way forward for alternative methods: formation of national consensus platforms in Europe. Toxicol Appl Pharmacol 2005; 207: 408-413

[67] Louisse J, Rijkers D, Stoopen G, Holleboom W], Delagrange M, Molthof E, Mulder PPJ, Hoogenboom RLAP, Audebert M, Peijnenburg AACM. Determination of genotoxic potencies of pyrrolizidine alkaloids in HepaRG cells using the $\gamma \mathrm{H} 2 \mathrm{AX}$ Assay. Food Chem Toxicol 2019; 131: 110532

[68] Gao L, Rutz L, Schrenk D. Structure-dependent hepato-cytotoxic potencies of selected pyrrolizidine alkaloids in primary rat hepatocyte culture. Food Chem Toxicol 2020; 135: 110923

[69] EC (European Commission). Commission Regulation (EU) 2020/2040 of December 112020 amending Regulation (EC) No 1881/2006 as regards maximum levels of pyrrolizidine alkaloids in certain foodstuffs. Off J EU L420/1. Accessed October 12, 2021 at: http://data.europa.eu/eli/reg/ 2020/2040/oj

[70] Lichtenstein D, Luckert C, Alarcan ], de Sousa G, Gioutlakis M, Katsanou ES, Konstantinidou P, Machera K, Milani ES, Peijnenburg A, Rahmani R, Rijkers D, Spyropoulou A, Stamou M, Stoopen G, Sturla SJ, Wollscheid B, Zucchini-Pascal N, Braeuning A, Lampen A. An adverse outcome pathway-based approach to assess steatotic mixture effects of hepatotoxic pesticides in vitro. Food Chem Toxicol 2020; 139: 111283

[71] Frei H, Lüthy J, Brauchli ], Zweifel U, Würgler FE, Schlatter C. Structure/ activity relationships of the genotoxic potencies of sixteen pyrrolizidine alkaloids assayed for the induction of somatic mutation and recombination in wing cells of Drosophila melanogaster. Chem Biol Interact 1992; 83: $1-22$

[72] Culvenor CC], Edgar JA, Jago MV, Outteridge A, Peterson JE, Smith LW. Hepato- and pneumotoxicity of pyrrolizidine alkaloids and derivatives in relation to molecular structure. Chem Biol Interact 1976; 12: 299-324

[73] DFG (Deutsche Forschungsgemeinschaft), Senatskommission zur Beurteilung der gesundheitlichen Unbedenklichkeit von Lebensmitteln (SKLM). Stellungnahme zu Pyrrolizidinalkaloiden in Honigen, Imkereierzeugnissen und Pollenprodukten. 2002. Accessed October 12, 2021 at: https://www.dfg.de/download/pdf/dfg_im_profil/reden_ stellungnahmen/2003/sklm_pa_honig_170403end.pdf

[74] EFSA (European Food Safety Authority: Scientific Committee). Opinion of the Scientific Committee on a request from EFSA related to a harmonised approach for risk assessment of substances which are both genotoxic and carcinogenic. Request No EFSA-Q-2004-020, adopted on October 18 2005. EFSA J 2005; 282: 1-31

[75] Molyneux RJ, Gardner DL, Colegate SM, Edgar JA. Pyrrolizidine alkaloid toxicity in livestock: a paradigm for human poisoning? Food Add Contam Part A 2011; 28: 293-307

[76] Culvenor CC. Estimated intakes of pyrrolizidine alkaloids by humans. A comparison with dose rates causing tumors in rats. J Toxicol Environ Health 1983; 11: 625-635

[77] Moreira R, Pereira DM, Valentão P, Andrade PB. Pyrrolizidine alkaloids: Chemistry, pharmacology, toxicology and food safety. Int J Molec Sci 2018; 19: E1668
[78] BGA (Bundesgesundheitsamt). Bekanntmachung über die Zulassung und Registrierung von Arzneimitteln vom 05. Juni 1992 Abwehr von Arzneimittelrisiken - Stufe II, hier: Arzneimittel, die Pyrrolizidin-Alkaloide mit einem 1, 2-ungesättigtem Necin-Gerüst enthalten. Bundesanzeiger 1992; 111: 4805

[79] NTP (National Toxicology Program). Bioassay of lasiocarpine for possible carcinogenicity. NTP Technical Report 1978; 39: 1-66

[80] NTP (National Toxicology Program). Toxicology and carcinogenesis studies of riddelliine. NTP Technical Report 2003; 508: 1-280

[81] EMA (European Medicines Agency). ICH guideline M7(R1) on assessment and control of DNA reactive (mutagenic) impurities in pharmaceuticals to limit potential carcinogenic risk (August 25, 2015). Accessed October 12, 2021 at: https://www.ema.europa.eu/en/ich-m7assessment-control-dna-reactive-mutagenic-impuritiespharmaceuticals-limit-potential

[82] EMA (European Medicines Agency). Public Statement on contamination of herbal medicinal products/traditional herbal medicinal products with pyrrolizidine alkaloids - Transitional recommendations for risk management and quality control (EMA/HMPC/328782/2016) (May 31, 2016) Accessed October 12, 2021 at: https://www.ema.europa.eu/ documents/public-statement/public-statement-contaminationherbal-medicinal-products/traditional-herbal-medicinal-productspyrrolizidine-alkaloids_en.pdf

[83] EMA (European Medicine Agency). Assessment report. Referral under Article 31 of Directive 2001/83/EC angiotensin-II-receptor antagonists (sartans) containing a tetrazole group Procedure no: EMEA/H/A-31/ 1471. EMA/217823/2019 (February 14, 2019). Accessed October 12, 2021 at: https://www.ema.europa.eu/en/documents/variation-report/ sartans-article-31-referral-chmp-assessment-report_en.pdf

[84] BfR (Bundesinstitut für Risikobewertung) German Federal Institute for Risk Assessment. Determination of pyrrolizidine alkaloids (PA) in botanical substances using SPE-LC-MS/MS. Description of the method. BfR-PA-Tee-2.0/2014. Accessed October 12, 2021 at: http://www.bfr. bund.de/cm/343/bestimmung-von-pyrrolizidinalkaloiden.pdf

[85] BfArM (Bundesinstitut für Arzneimittel und Medizinprodukte). Bekanntmachung zur Prüfung des Gehalts an Pyrrolizidinalkaloiden zur Sicherstellung der Qualität und Unbedenklichkeit von Arzneimitteln, die pflanzliche Stoffe bzw. pflanzliche Zubereitungen oder homöopathische Zubereitungen aus pflanzlichen Ausgangsstoffen als Wirkstoffe enthalten (March 1, 2016). Accessed October 12, 2021 at: https:// www.bfarm.de/SharedDocs/Bekanntmachungen/DE/Arzneimittel/ besTherap/bm-besTherap-20160301-pa-pdf.html

[86] EMA (European Medicines Agency). HMPC meeting report on European Union herbal monographs, guidelines and other activities. The 86th HMPC meeting, held on 14-16 January 2019 (EMA/HMPC/26549/2019) (January 16, 2019). Accessed October 12, 2021 at: https://www.ema. europa.eu/documents/committee-report/hmpc-meeting-reporteuropean-union-herbal-monographs-guidelines-other-activities14-16-january-2019_en.pdf

[87] EMA (European Medicines Agency). Public statement on the use of herbal medicinal products containing toxic, unsaturated pyrrolizidine alkaloids (PAs) including recommendations regarding contamination of herbal medicinal products with pyrrolizidine alkaloids. Final (July 7, 2021). Accessed October 12, 2021 at: https://www.ema.europa.eu/en/ documents/public-statement/draft-public-statement-use-herbalmedicinal-products-containing-toxic-unsaturated-pyrrolizidine_en-0. pdf 